\title{
Metal Salen- and Salphen-Containing Organic Polymers: Synthesis and Applications
}

\author{
Sven M. Elbert ${ }^{a}$ \\ Michael Mastalerz ${ }^{* a}$ \\ ${ }^{a}$ Organisch-Chemisches Institut, Ruprecht-Karls-Universität Heidelberg, Im \\ Neuenheimer Feld 270, 69120 Heidelberg, Germany \\ Michael.mastalerz@oci.uni-heidelberg.de
}

Received: 13.12 .2019

Accepted after revision: 4.02.2020

DOI: 10.1055/s-0040-1708501; Art ID: 190025rev License terms: (c)

(c) 2019. The Author(s). This is an open access article published by Thieme under the terms of the Creative Commons Attribution-NonDerivative-NonCommercial-License, permitting copying and reproduction so long as the original work is given appropriate credit. Contents may not be used for commercial purposes, or adapted, remixed, transformed or built upon. (https://creativecommons.org/licenses/by-nc-nd/4.0/).

Abstract The properties of organic polymeric materials can be chemically fine-tuned by the implementation of functional groups or units within the backbone. Especially the inclusion of coordinated metal centers offers a nearly infinite toolbox to adjust properties and thus potential applications. In particular, salen and salphen complexes are widely known to be highly efficient homogenous catalysts. They are also used as luminescent materials and devices or as supramolecular building blocks. This review focusses on the class of salen- and salphencontaining organic polymers, from 1D to 3D. Besides the comparison of synthetic polymerization methods, properties and applications are discussed, with an emphasis on porous 2D and 3D polymeric metal salphens and salens for heterogeneous catalysis and gas sorption.

Key words Porous polymers, heterogeneous catalysis, conductive films, salens, salphens, gas sorption

\section{Introduction}

The imine condensation of two equivalents of salicylaldehyde with one equivalent of 1,2-ethylene- or phenylene diamine is the underlying reaction to synthesize the ligand classes called salens and salphens (sometimes also named salophens) (Figure 1). Since the first discovery of the structurally related acacen ligand in 1889 by Combes, ${ }^{1}$

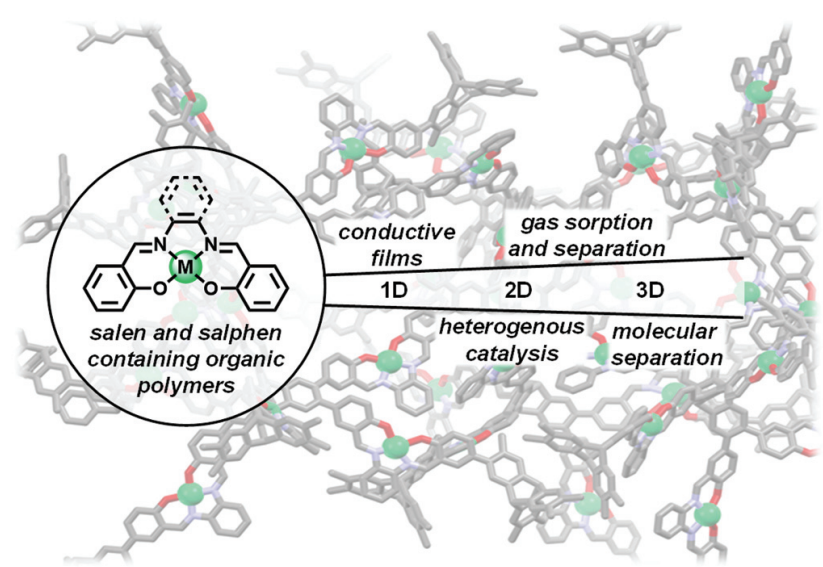

numerous $\mathrm{N}_{2} \mathrm{O}_{2}$ ligands ${ }^{2}$ such as salans, ${ }^{3}$ salalens, ${ }^{4}$ salamos, ${ }^{5}$ or their thio-derivatives ${ }^{6}$ have been developed (Figure 1). Among all $\mathrm{N}_{2} \mathrm{O}_{2}$ ligands, the salens and salphens are probably the most commonly used ones. ${ }^{7}$ The most prominent congeners are the $\mathrm{Mn}(\mathrm{III})$-salens developed by Jacobsen (1991) and Katsuki (1994) for the enantioselective epoxidation of unfunctionalized olefins. ${ }^{8}$ Inspired by this reaction, metal salen complexes have been successfully used as catalysts for a broad range of asymmetric reactions, such as hydroxylations, ${ }^{9}$ cyclopropanations ${ }^{10}$ and several other

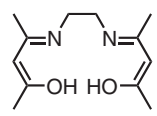

acacen (Combes 1889)
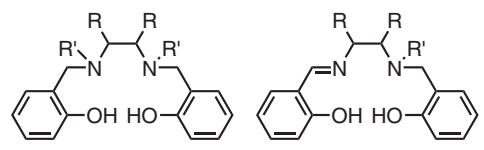

Salalen
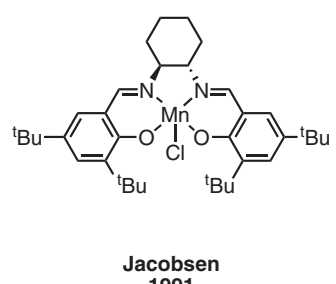

1991

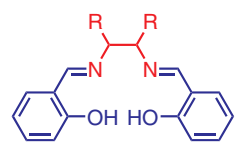

Salen

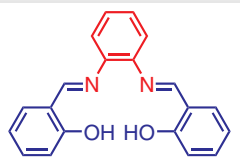

Salphen

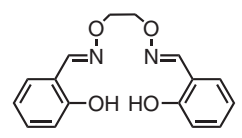

Salamo

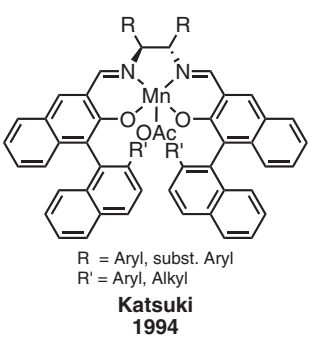

Figure 1 Molecular structures of selected $\mathrm{N}_{2} \mathrm{O}_{2}$ ligands. ${ }^{8 \mathrm{~b} 1}$ 
Biographical Sketch
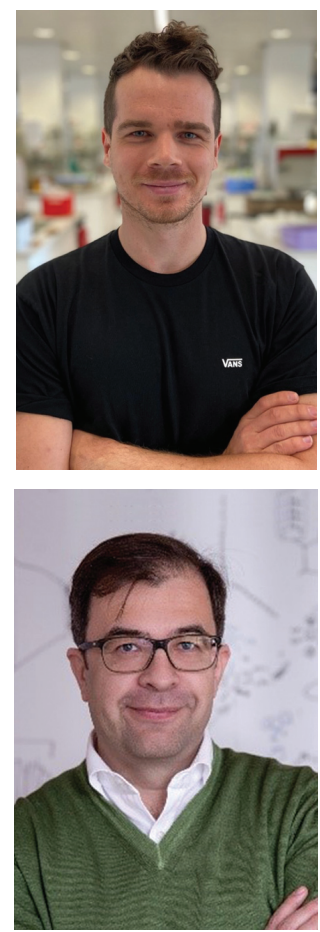

Michael Mastalerz studied Chemistry at the Gerhard-Mercator University of Duisburg and after 9 semesters received his diploma (which was awarded by the University) in 2002. He followed Prof. Dr. Gerald Dyker to the Ruhr-University of Bochum to pursue his PhD studies, receiving his doctoral degree in 2005 with distinction (summa cum laude). After a short stay in industry he thesis. He joined the Mastalerz group moving to the Ruprecht-Karls-University of Heidelberg in 2013 to conduct his PhD studies (supported by a scholarship of Studienstiftung des Deutschen Volkes), obtaining the doctoral degree with distinction (summa cum laude) in 2018. Since then, he is the scientific coordinator in the Mastalerz group, focusing his research on porous materials as well as $\pi$-extended nonplanar molecules. oxidation reactions, ${ }^{11}$ aziridinations, ${ }^{12}$ epoxide-ring opening reactions, ${ }^{13}$ hetero-Diels-Alder reactions, ${ }^{14}$ or trimethylsilylcyanations. ${ }^{7, a, c, 15}$

As mentioned above, all the described ligands provide an $\mathrm{N}_{2} \mathrm{O}_{2}$ binding site in a square planar geometry, suitable for binding a large variety of metal ions well as ions of main group elements. With a few exceptions, such as the elements of the 7th period or the bigger alkali metals, salphen or salen complexes with nearly all other metals of the periodic system of the elements have been realized (Figure 2), such as with $\mathrm{Li}^{+},{ }^{16} \mathrm{Be}^{2+},{ }^{17} \mathrm{Na}^{+},{ }^{18} \mathrm{Mg}^{2+},{ }^{19} \mathrm{Al}^{3+}, 20$ $\mathrm{Si}^{4+},{ }^{21} \mathrm{P}^{3+},{ }^{22} \mathrm{Ca}^{2+},{ }^{23} \mathrm{Sc}^{3+},{ }^{24} \mathrm{Ti}^{4+},{ }^{25} \mathrm{~V}^{4+},{ }^{26} \mathrm{Cr}^{3+},{ }^{27} \mathrm{Mn}^{3+}, 8 \mathrm{~b}$
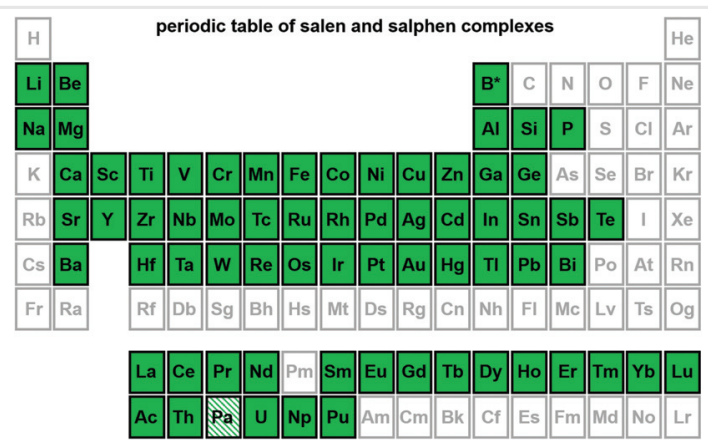

complex described in Literature

complex mentioned in Literature but not isolated

Figure 2 Periodic table of the elements. The elements which ions have been used for salen and salphen complexes are highlighted in green. joined the group of Prof. Dr. Gregory Fu at the Massachusetts Institute of Technology in the United States in 2006 to work on asymmetric crosscoupling reactions. In 2007 he moved back to Germany to Ulm University affiliated to the group of Prof. Dr. Peter Bäuerle to start his independent career working on porous materials and molecules. He received his venia legendi in
February 2013 and subsequently (April 2013) got a position at the Ruprecht-Karls-University of Heidelberg as a full professor. Currently, he is an ERC Consolidator Grant holder. His research focusses on organic cage compounds, porous polymeric materials, supramolecular chemistry, nonplanar extended aromatic molecules as well as the development of new synthetic methods.

$\mathrm{Fe}^{2+}, 28 \mathrm{Fe}^{3+29} \mathrm{Co}^{2+30} \mathrm{Co}^{3+31} \mathrm{Ni}^{2+32} \mathrm{Cu}^{2+33} \mathrm{Zn}^{2+34}$ $\mathrm{Ga}^{3+}, 35 \mathrm{Ge}^{2+/ 4+}, 36 \mathrm{Sr}^{2+}, 23 \mathrm{Y}^{3+}, 37 \mathrm{Zr}^{4+}, 38 \mathrm{Nb}^{5+}, 39 \mathrm{Mo}^{4+}, 40$ $\mathrm{Tc}^{5+},{ }^{4} 1 \mathrm{Ru}^{3+}, 42 \mathrm{Rh}^{3+},{ }^{3} \mathrm{Pd}^{2+},{ }^{44} \mathrm{Ag}^{+},{ }^{45} \mathrm{Cd}^{2+},{ }^{46} \mathrm{Sb}^{5+},{ }^{\prime} \mathrm{Te}^{4+},{ }^{4}$

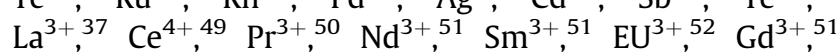
$\mathrm{Tb}^{3+}, 51 \mathrm{Dy}^{3+51} \mathrm{Ho}^{3+53} \mathrm{Er}^{3+51} \mathrm{Tm}^{3+53} \mathrm{Yb}^{3+53} \mathrm{Lu}^{3+}{ }^{3+}$ $\mathrm{Hf}^{4+},{ }^{4} \mathrm{Ta}^{5+},{ }^{5} \mathrm{~W}^{6+},{ }^{56} \mathrm{Re}^{4+},{ }^{57} \mathrm{Os}^{4+}, 58 \mathrm{Ir}^{3+}, 59 \mathrm{Pt}^{2+}, 60 \mathrm{Au}^{3+61}$ $\mathrm{Hg}^{2+},{ }^{46} \mathrm{Tl}^{3+}, 62 \mathrm{Bi}^{3+}, 63 \mathrm{Th}^{4+}, 64 \mathrm{U}^{6+}, 65 \mathrm{~Np}^{5+}, 66$ or $\mathrm{Pu}^{4+} .49$

In contrast to metal salens, for which comparably simple chiral diamines can be used to introduce chirality, metal salphen complexes lack of $\mathrm{sp}^{3}$-hybridized centers and chirality can be introduced by the use of more sophisticated chiral building blocks such as biaryls, ${ }^{67}$ helicenes, ${ }^{68}$ and calixarenes, ${ }^{69}$ or upon supramolecular chiral induction. ${ }^{70}$ Therefore, salphen complexes are rarely used for enantioselective reactions. Despite this disadvantage, metal salphens were able to catalyze polymerizations ${ }^{71}$ or fix $\mathrm{CO}_{2}$ as cyclic carbonates. ${ }^{72}$ For the latter, Lewis acidic zinc-salphens have been used, which are able to coordinate reactants to the axial positions of the square-planar coordination sphere and thus activate them for nucleophilic attacks. ${ }^{73}$ Besides mononuclear complexes, the formation of salens and salphens was also used to create multinuclear, ${ }^{74}$ macrocyclic, ${ }^{75}$ or cage-like ligands ${ }^{76}$ and their corresponding metal complexes (for selected examples, see Figure 3). Such structures have been achieved by dynamic covalent chemistry (DCC). ${ }^{77}$

Another approach to embed salen or salphen moieties into more complex structures is realized by the decoration of molecules with functional groups enabling additional 


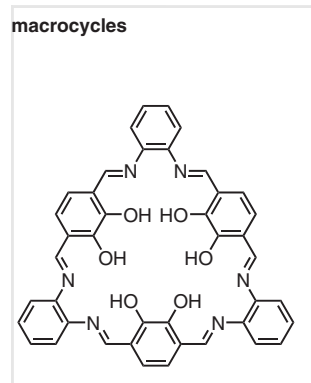

cages
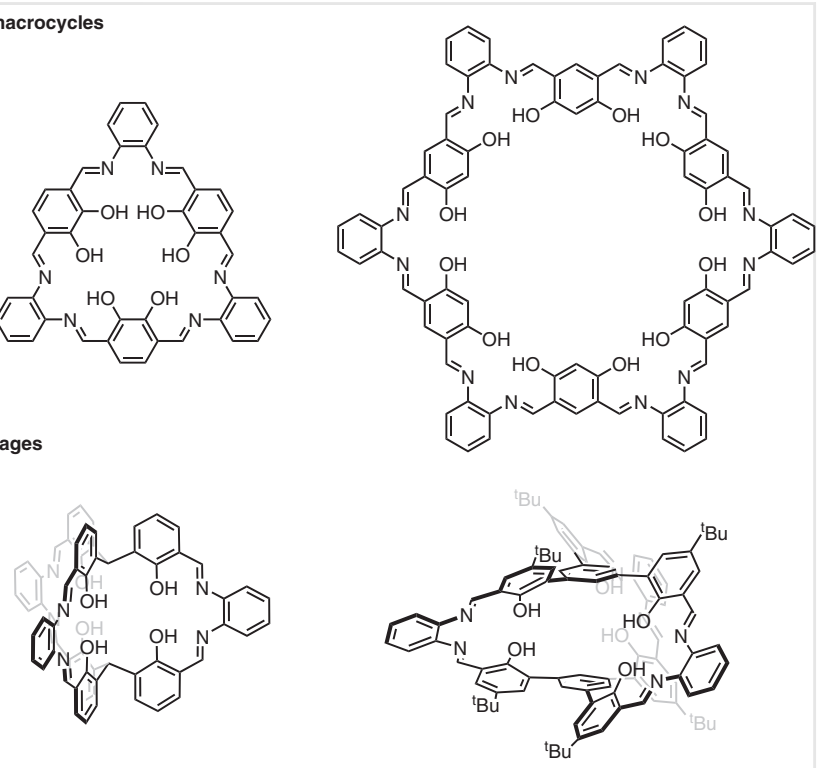

Figure 3 Top: macrocyclic [3 +3$]$ - and $[6+6]$-salphen ligands reported by the groups of Nabeshima ${ }^{75 b}$ and MacLachlan. ${ }^{75 c}$ Bottom: cage-like $[2+3]$-salphen ligands reported by Nabeshima and coworkers. ${ }^{76 \mathrm{~d}, 76 \mathrm{e}}$

coordinative binding sites and therefore being able to act as building blocks for supramolecular boxes, ${ }^{78}$ coordination cages, ${ }^{79}$ coordinatively bound macrocycles, ${ }^{80}$ or metalorganic frameworks (MOFs). ${ }^{81}$ The immobilization of soluble salens or salphens in polymeric materials such as MOFs nicely allows to exploit the good catalytic activity in a heterogeneous approach. ${ }^{81 \mathrm{~s}, \mathrm{t}, \mathrm{v}, \mathrm{x}, \mathrm{z}-\mathrm{ac}}$ Similar to that, these MOFs were used for gas separation ${ }^{81 u}$ or storage, ${ }^{81 y}$ chiral resolution, ${ }^{81 \mathrm{w}}$ and many more. The insoluble salen-containing MOFs can efficiently be recycled after use, which is a common technique when expanding the application of soluble complexes to the heterogeneous phase by immobilization. ${ }^{82}$ However, most MOFs including the aforementioned salen MOFs contain metal nodes which suffer from instability against aqueous acidic or basic media. This limits their potential applications and typically stabilization techniques such as post-synthetic coating or guest addition have to be used to circumvent a quick degradation. ${ }^{83}$

This review highlights salen- and salphen-based materials embedded in fully covalent-bonded polymeric backbones. The objective of this review is to summarize and compare the different synthetic strategies, to examine the advantages and disadvantages of the different approaches based on the resulting material properties, and to give an overview of the structures reported to date. Furthermore, the potential applications of these compounds will be highlighted with selected examples. The review does not cover those salphen-containing superstructures based on the formation of coordinative bonds, which have been discussed in other recent excellent reviews. ${ }^{84}$

\section{Structural Dimensionality}

We arbitrarily divide salen and salphen polymers into 1D, 2D, or 3D by their idealized topology in terms of the propagation of the monomeric building blocks rather than by the real orientation in space by coiling, folding, steric effects, or contortion. First of all, we give an overview of how the different polymers have been synthesized and then discuss their properties.

\section{D-Salen and Salphen Polymers}

The construction of salen- or salphen-containing polymers can in principal be divided into two main synthetic strategies. One strategy is based on the formation of the salen or salphen pocket during the condensation (polymerization) reaction with or without simultaneous complexation of metal ions. The other strategy is to use the preformed salen or salphen moieties, acting as monomers, in polymerization reactions like electropolymerizations, ${ }^{85}$ cross-coupling reactions, ${ }^{86}$ or comparable polymerization reactions. ${ }^{87}$ Both strategies have been applied in the synthesis of $1 \mathrm{D}$ salen and salphen polymers.

The first polysalphens were described in the late 1950s by Marvel and Tarköy, synthesized by the condensation of methylene- ${ }^{88}$ and sulfone-bridged ${ }^{89}$ bissalicylaldehydes with ortho-phenylene diamine (Scheme 1). By treatment

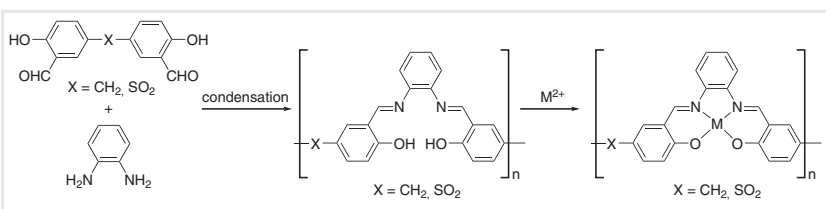

Scheme 1 Syntheses of the first polysalphens reported by Marvel and Tarköy. ${ }^{88,89}$

of the metal-free polymers with THF-solutions of $\mathrm{Zn}^{2+}$, $\mathrm{Cu}^{2+}, \mathrm{Fe}^{2+}, \mathrm{Ni}^{2+}, \mathrm{Co}^{2+}$, and $\mathrm{Cd}^{2+}$ salts, a large variety of metal-containing salphen polymers were obtained. By the assumption that the polymers are pure, monodisperse, and do not contain solvate or other impurities, the polymers had lengths up to 45 repeating units according to the interpretation of elemental analysis results. ${ }^{88}$ The thermal stabilities of the polymers were investigated, showing that the coordinated metal centers had a stabilizing effect. Furthermore, an enhancement in thermal stability was achieved by formal exchange of the methylene bridges by sulfone bridges. This was attributed to the higher acidity of the phenolic oxygen atom due to electron-withdrawing effects of the para-substituted sulfone in comparison to the methylene tethers. ${ }^{88,89}$ It must be noted that at that time the analyses of the thermal stability relied on weight losses exclusively. However, in principle the observations could 

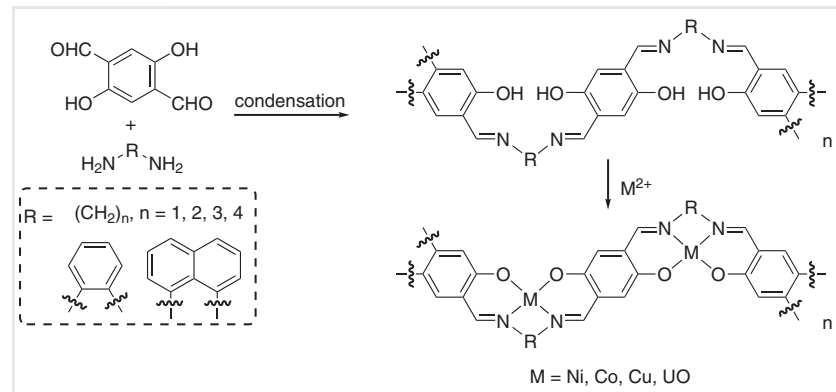

Scheme 2 Polysalens and polysalphens based on the condensation of 2,5-dihydroxyterephthalaldehyde with diamines. ${ }^{90}$

also be attributed to, for example, the release of bound water molecules.

A similar approach based on 2,5-dihydroxyterephthalaldehyde (Scheme 2) was reported at the beginning of the 1970s by Manecke and Wille. ${ }^{90}$ Here, the structural variety was achieved by using different diamines for the condensation. The conductivity of the fully conjugated 1D-polymers was measured and the authors concluded that the complexation of the metal centers is beneficial for the conductivity by increasing the rigidity of the polymeric backbone. The metalated polymers had up to five times higher conductivities $\left(10^{-10} \mathrm{~S} \mathrm{~m}^{-1}\right)$ in comparison to the free ligands, but regarding the nature of the metal used no trend was found. ${ }^{90 b}$

Besides the early examples of salphen polymers synthesized by condensation of amines and aldehydes, the second strategy used was the electropolymerization of presynthesized salen and salphen compounds introduced by Goldsby and coworkers in $1988 .^{91}$ This so-called potentiostatic method gave a structurally less defined nickel(II) salen-containing film on the surface of a platinum disc electrode (Scheme 3). ${ }^{91,92}$ Later, this approach was reinvestigated by others. ${ }^{93}$ Within these studies it was revealed that for the aforementioned film "...the electropolymerization of [Ni(salen)] is ultimately a ligand-based process that takes place through a mixture of o- and p-linking of the phenyl rings..." (Scheme 3). ${ }^{93 \mathrm{~b}}$ Despite these irregular structures, a clear difference of the chemical as well as physical properties of the synthesized polymer films in comparison to aggregated individual Ni-salen complexes was confirmed by IR, UV/vis, and EPR spectroscopy and the redox and charge conduction behaviors were studied. ${ }^{93 \mathrm{~b}}$

To obtain a $1 \mathrm{D}$ polymer chain in a regioselective manner, Reynolds and coworkers used 3,4-diaminothiophene as well as terthiophenes to synthesize $\mathrm{Ni}$-and $\mathrm{Cu}$-salphens, which were electropolymerized to give conjugated polythiophenes with salphens ${ }^{94 a}$ and salphen/crown-ether moieties ${ }^{94 b}$ (Scheme 3). Swager and coworkers followed a slightly different approach to achieve control over the electrochemical properties of the polymers. ${ }^{94 \mathrm{c}}$ They synthesized a Cosalen moiety with thienyl substituents in the para-position

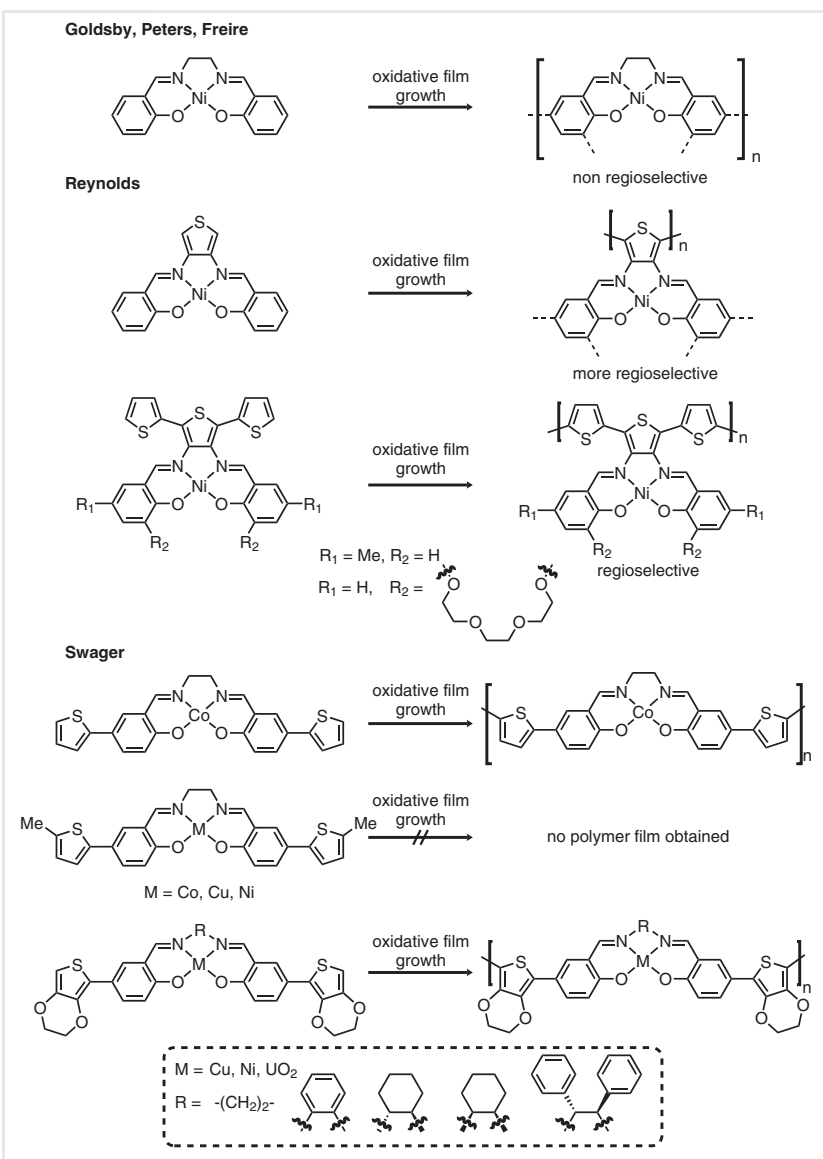

Scheme 3 Polysalens and polysalphens synthesized by electropolymerization. ${ }^{91-94}$

to the phenolic oxygen (Scheme 3). ${ }^{94 \mathrm{c}}$ The regioselective electropolymerization on the thiophene's vacant $\alpha$-position was proven by hindered film growth when this position was blocked by methyl substituents. ${ }^{94 \mathrm{c}}$ This detailed structureactivity relationship was further studied on a series of electropolymerized materials derived from poly(3,4-ethylenedioxythiophene) (PEDOT)-substituted $\mathrm{Cu}(\mathrm{II}), \mathrm{Ni}(\mathrm{II})$, and $\mathrm{U}(\mathrm{VI}) \mathrm{O}_{2}$ salens (Scheme 3 ). The interchain spacing was modulated by the use of different sterically bulky ethyleneand phenylene-diamines. It was found that large chainchain interactions lower the oxidation potentials of the salen units due to destabilizing interactions of the corresponding HOMOs, which lead to the formation of spin-paired $\pi$-dimers upon further oxidation. In contrast to that, sterically shielded, noninteracting chains create radical cations and subsequent dications by oxidation. ${ }^{95}$ It is worth mentioning that the potentiostatic method has been used exclusively for the synthesis of $1 \mathrm{D}$ polymer films so far. Also other nanostructures such as nanowires ${ }^{96}$ or nitric oxide sensors are based on this type of polymerization. ${ }^{97}$ Additionally, this approach was used to develop composite materials of metal salphen or salen complexes with 
multiwalled carbon nanotubes (MWCNTs) as capacitive materials ${ }^{98}$ and in the synthesis of high-capacity films (see discussion below). ${ }^{99}$

As known from nature, 1D polymers can also create superstructures of high complexity such as the DNA double helices. ${ }^{100}$ Already in 1996, Katz and coworkers synthesized fully conjugated $1 \mathrm{D}$ helical ladder polymers based on the condensation of a [6]-helicene bissalicylaldehyde with 1,2-phenylene diamine in the presence of nickel(II) acetate (Scheme 4). ${ }^{68 a}$ According to the integration of characteris-

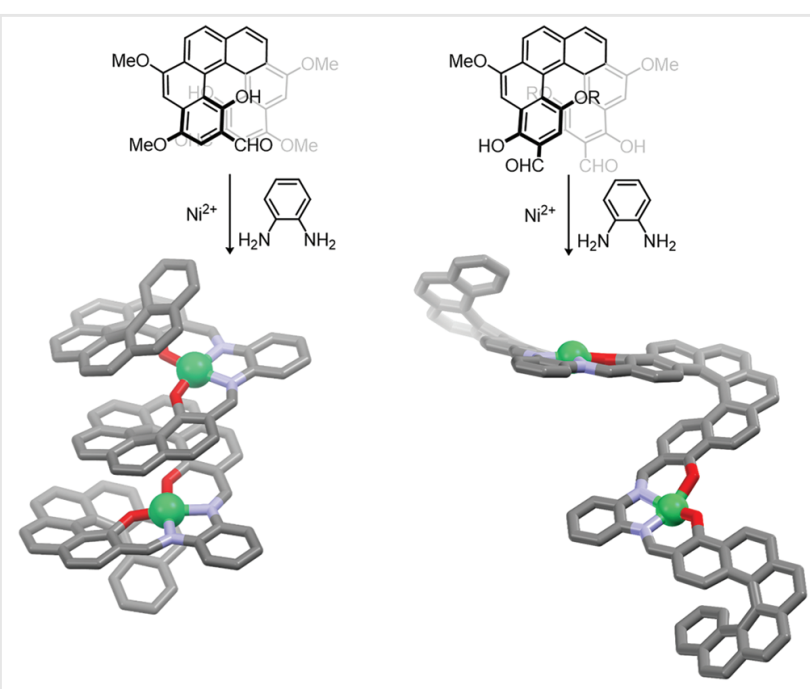

Scheme 4 Synthesis of helical polymers from enantiomerically pure bissalicylaldehydes and ortho-phenylene diamine. ${ }^{68}$ Sections of the polymeric helices are depicted as MM2-optimized models.

tic signals in ${ }^{1} \mathrm{H}$ NMR-spectra as well as by gel permeation chromatography (GPC) analyses the average molecular mass of the polymers was estimated to be about 7,000-7,400 Da, which corresponds to approximately eight repeating units. The fully conjugated character of the metal salphen helix was indicated by a bathochromic shift of $114 \mathrm{~nm}$ of the metal-to-ligand charge transfer band in comparison to simple nickel(II) salphen complexes in the UV/vis spectra. ${ }^{68 a}$ At the most redshifted absorption maximum $\left(\lambda_{\mathrm{abs}}=595 \mathrm{~nm}\right)$, a large circular dichroism (CD) of $\Delta \varepsilon=105$ was found. Furthermore, by the variation of the substitution pattern on the enantiopure regioisomeric [6]-helicene bissalicylaldehydes, different winding motifs within the corresponding chiral helicenes were realized as depicted in Scheme $4 .{ }^{68 \mathrm{~b}}$

Another example of helical 1D metal salphen polymer was obtained by the condensation of chiral 3,3'-diformylbinaphthol derivatives with various $\alpha, \omega$-diamines and subsequent complexation of $\mathrm{Zn}^{2+}$ - or $\mathrm{Mn}^{2+}$-ions (Scheme 5). ${ }^{101}$ The chiral helices showed clear differences in $\mathrm{CD}$-spectroscopy by decreased Cotton effects at $\lambda=230 \mathrm{~nm}$ for the helical
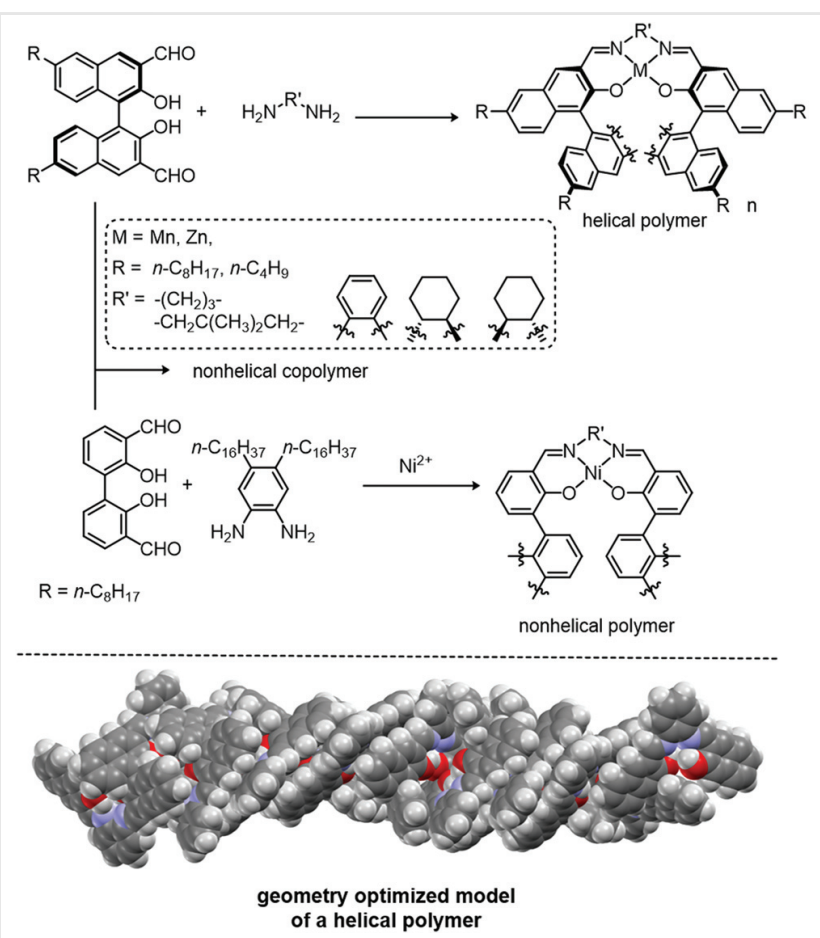

Scheme 5 Synthesis of helical polymers from enantiomerically pure dinaphthyl-bissalicylaldehyde and different $\alpha, \omega$-diamines. ${ }^{101}$ Section of the polymeric helix is depicted as a geometry-optimized model (MMFF94, MM2)

polymers in comparison to mononuclear model compounds. Furthermore, the aforementioned band at $\lambda=230 \mathrm{~nm}$, which is assigned to the naphthalene subunits, redshifted approximately about $\Delta \lambda=30 \mathrm{~nm}$, which is a hint for a close proximity of adjacent naphthalene units as proposed by geometry optimized models (MMFF94 and MM2)(Scheme 5). By GPC analyses, average molecular masses of up to $13,000 \mathrm{Da}$ (approximately 10 repeating units) were estimated. ${ }^{101 b}$ Interestingly, the helical induction of the binaphthol units is not transferred to polymer chains when copolymerized with biphenyl bissalicylaldehyde in various ratios (from 100:0 to $0: 100$ ) in the presence of a soluble phenylenediamine and nickel(II) acetate (Scheme 5). ${ }^{67}$

Also worth mentioning is a superstructure that was presented by Houjou and coworkers in 2003. Two strands of linear polysalicylimines build a double-helix by the formation of salen-like moieties after complexation of $\mathrm{Zn}^{2+}, \mathrm{Ni}^{2+}, \mathrm{Co}^{2+}$, and $\mathrm{Cu}^{2+}$ ions. The resulting polymers formed microspheres with diameters between 0.5 and $1.4 \mu \mathrm{m}$ indicating ordered materials on the macroscopic scale (Scheme 6). ${ }^{102}$

In 2002, Lavastre et al. used palladium-catalyzed Sonogashira-Hagihara cross-coupling reactions the first time to synthesize 1D metal salphen polymers (Scheme 7). ${ }^{103} \mathrm{~A}$ library of different linear polysalphens with $\mathrm{Ni}(\mathrm{II})$ - as well as $\mathrm{Zn}(\mathrm{II})$-metal centers and various dialkynes as linking units (among several polymers without salphen units) were 

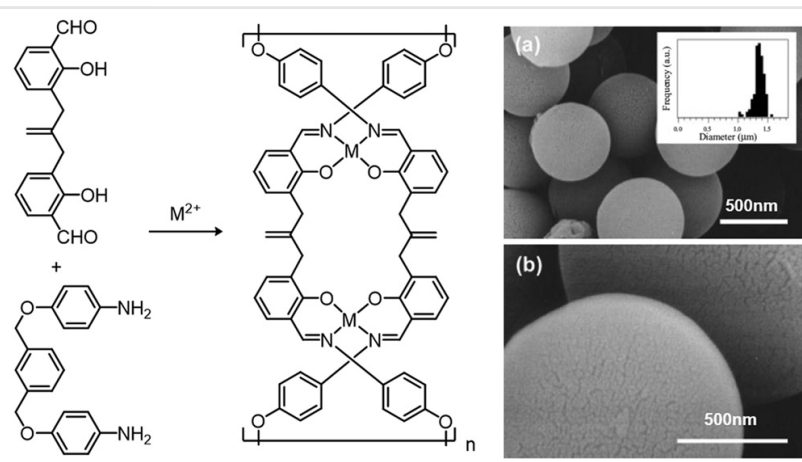

Scheme 6 Left: synthesis of Houjou's linear polyimines interconnected by salen-like moieties. ${ }^{102}$ Right: SEM micrographs of $\mathrm{Cu}(\mathrm{II})$ polymers creating microspheres. (Parts of the scheme are adapted with permission from Ref. 102. Copyright @ 2003 WILEY-VCH Verlag GmbH Co. KGaA, Weinheim.)
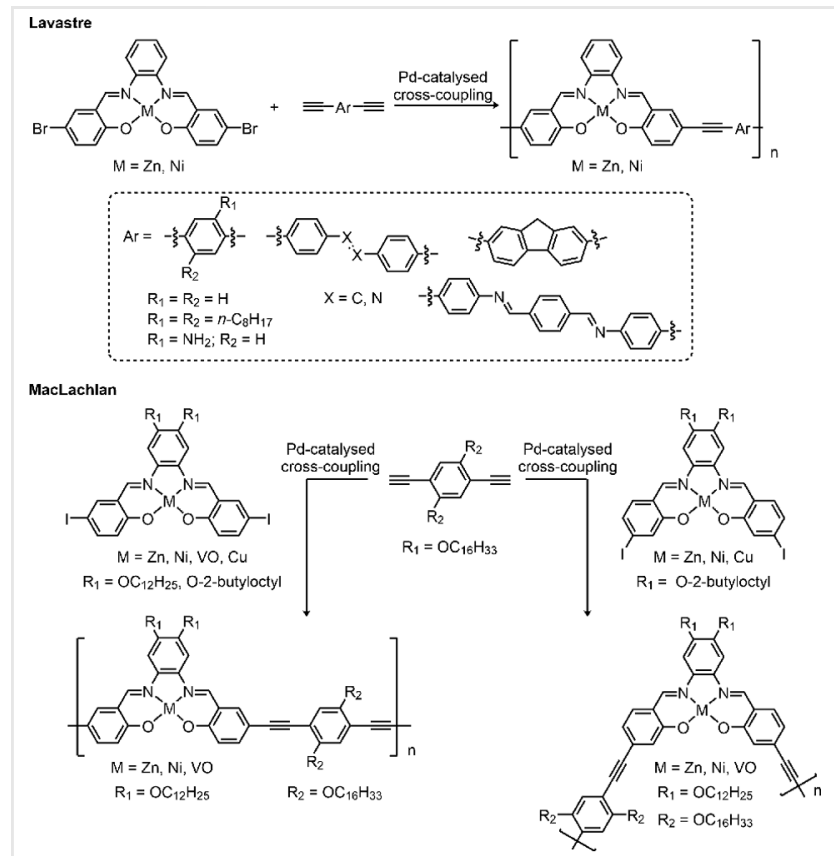

Scheme 7 Synthesis of 1D-polysalphens by palladium-catalyzed Sonogashira-Hagihara cross-coupling. ${ }^{103,104}$

generated. The corresponding polymers emitted light in solution but were unfortunately no potential candidates for organic light-emitting diodes (OLEDs) due to quenched solidstate emission. ${ }^{103}$

MacLachlan and coworkers used a similar method to obtain soluble poly(salphen-alkyne)s with $\mathrm{Zn}^{2+}, \mathrm{Ni}^{2+}$ as well as $\mathrm{VO}^{2+}$ centers. ${ }^{104 a}$ GPC analyses revealed high molecular masses of $17,000 \mathrm{Da}$ for the Ni-salphen and up to 84,000 for the VO-salphen polymer (Scheme 7). Furthermore, by the variation of the substitution pattern of the halogens at the salphen units, helical or zig-zag-type polysalphen chains with
$\mathrm{Zn}^{2+}, \mathrm{Ni}^{2+}$, and $\mathrm{Cu}^{2+}{ }^{104 b}$ as well as with $\mathrm{Pt}^{2+}$ centers have been realized. ${ }^{105}$ Furthermore, different external substituents like saccharines were used as well. ${ }^{105,106}$

An interesting example of a 1D salphen polymer with an ordered 3D structure was presented by Liu and coworkers in 2015 by condensing a bissalicylaldehyde and phenazine diamine with zinc acetate. ${ }^{107}$ It is suggested that due to the extended aromatic backbone of the precursors, the resulting polymer chains pack in an ordered fashion to form crystalline supramolecular 3D networks. Crystallinity of the material was proven by scanning electron microscopy and powder X-ray diffraction (PXRD; Scheme 8). Interestingly, it was reported that these polymers are permanently porous, having a specific
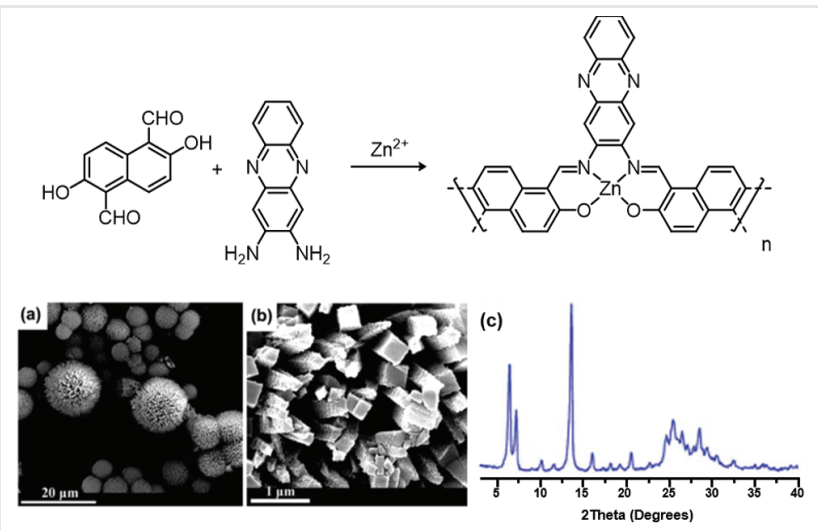

Scheme 8 Top: synthesis of Liu's 1D Zn(II) salphen polymer from a naphthalene bissalicylaldehyde and 2,3-diaminophenazine. Bottom: SEM micrographs of the obtained microspheres (a) and rods (b), and PXRD pattern of the corresponding material (c). ${ }^{107}$ (Parts of the scheme are adapted with permission from Ref. 107. Copyright @ 2015 The Polymer Society of Korea and Springer.)

surface area of $\mathrm{SA}_{\mathrm{BET}}=206 \mathrm{~m}^{2} / \mathrm{g} .{ }^{107}$ The non-local density functional theory (NLDFT) pore size distribution showed a maximum in the microporous regime with $d_{\text {pore }}=1.4 \mathrm{~nm}$ and mesoporous proportions with $d_{\text {pore }}=2.5$ and $4.4 \mathrm{~nm}$. Unfortunately, no structural model was suggested on how these highly defined pores are generated by the packing of the linear polymer strands in the crystalline state. ${ }^{107}$

Other methods such as the epoxy polymerization ${ }^{108}$ or Gilch polymerization ${ }^{109}$ have been used to synthesize 1D polysalphens. For the polymers derived from these methods as well as for several ionic polymers, ${ }^{110}$ no structural suggestions were made.

\section{D-Salen and Salphen Polymers}

By structural modification of the molecular building blocks, 2D salen and salphen polymers can be realized. 
Although the first 1D polymers were reported in 1954 (see above), half a century had to pass until Gothelf and coworkers presented the first 2D salen polymer in 2005. ${ }^{111}$ The condensation of a $C_{3}$-symmetric trissalicylaldehyde and ethylene diamine ${ }^{111}$ gave a metal-free network (Scheme 9) with at least locally ordered structures as

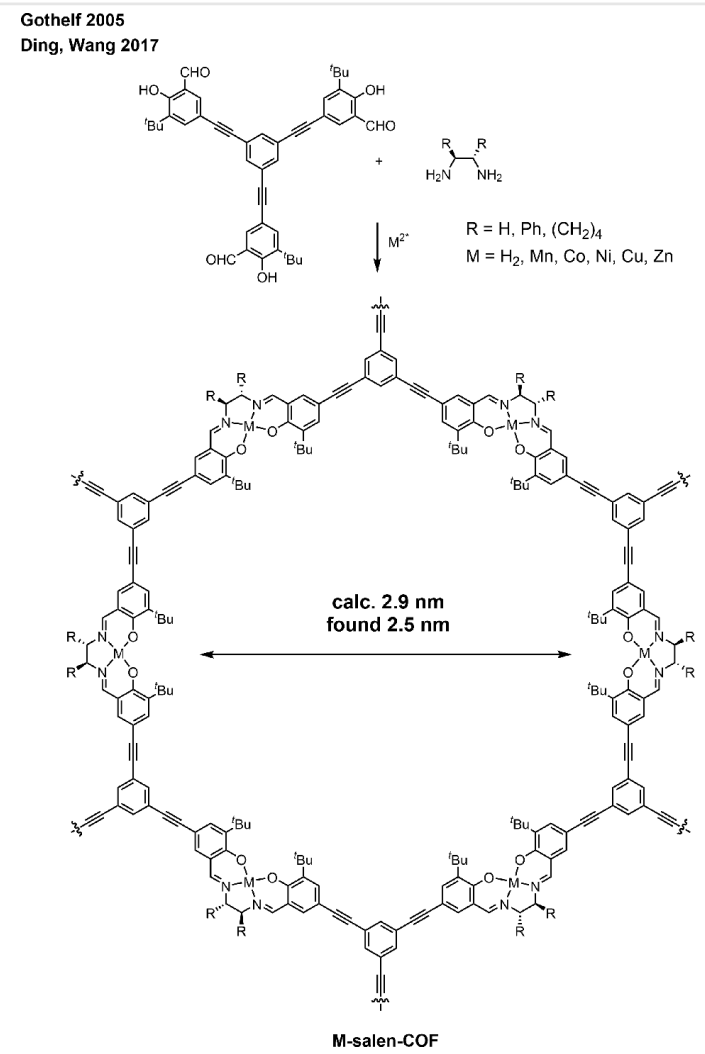

Scheme 9 Structural motifs of salen-containing 2D polymers and calculated as well as experimentally measured pore sizes. ${ }^{111,112}$

determined by PXRD. Interestingly, when condensed with chiral ethylene diamines, the presence of $\mathrm{Mn}$ (II)-acetate was necessary to observe a comparable PXRD signal pattern. ${ }^{111}$ Ding, Wang, and coworkers optimized the reaction conditions of the same reaction in 2017 and synthesized a structurally related material with high crystallinity by solvothermal methods (dioxane, ethanol, acetic acid, $120^{\circ} \mathrm{C}$, $3 \mathrm{~d}) .{ }^{112}$ By NLDFT calculations a pore-size distribution with a maximum diameter of $2.5 \mathrm{~nm}$ was found, fitting to the expected mesopore size of $2.9 \mathrm{~nm}$ according to the proposed eclipsed alignment of the $2 \mathrm{D}$ polymer sheets. ${ }^{112}$ After subsequent metalation, the M-salen covalent organic frameworks (COFs) with $\mathrm{Cu}(\mathrm{II})-, \mathrm{Ni}(\mathrm{II})-, \mathrm{Zn}(\mathrm{II})-, \mathrm{Co}(\mathrm{II})-$, and $\mathrm{Mn}$ (II)-metal centers were obtained. It is worth mentioning that for both the unsubstituted $(\mathrm{pH}=1-13)$ and $\mathrm{Co}(\mathrm{II})-$ salen $(\mathrm{pH}=2-13)$ COFs, high chemical stabilities were reported.
Liu and Cui just prior to Yang and coworkers synthesized further salen COFs using salicylaldehydes with 1,3,5triphenylbenzene as the core structure in condensation reactions (Scheme 10). ${ }^{113}$ Liu and Cui first synthesized chiral Zn-salen-COFs (CCOF-3) and pointed out that the stability of the COFs differs with changing substituents $(\mathrm{H}$

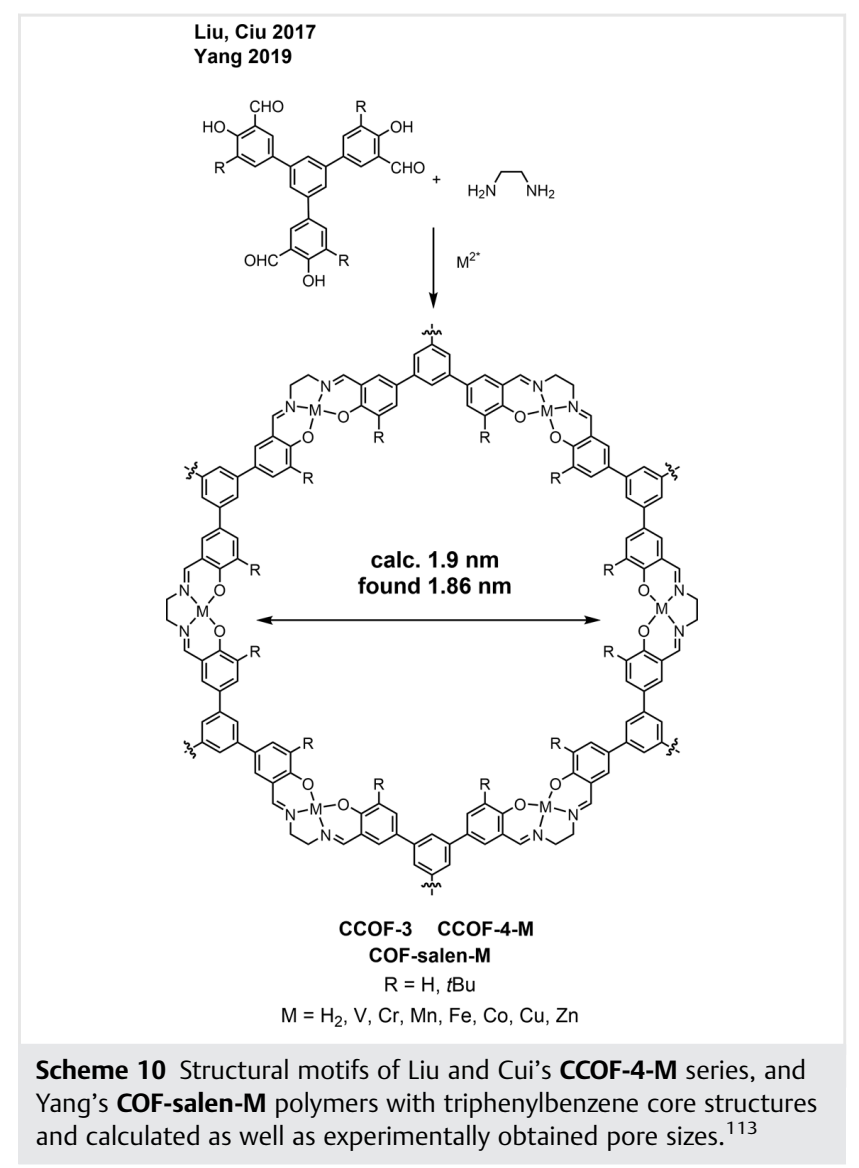

vs. ${ }^{\mathrm{t}} \mathrm{Bu}$ ) of the salicylaldehyde units with a higher stability of tert-butyl-substituted COFs due to "kinetic blocking." ${ }^{113 a}$ After transmetalation, ${ }^{114}$ mixed metal networks with $\mathrm{Zn}(\mathrm{II})$ and one or two other metal ions were obtained (CCOF-4-M). The exact metal ratios were determined by inductively coupled plasma optical emission spectroscopy (ICP-OES).

Yang and coworkers followed the approach of first synthesizing the metal-free $\mathrm{COF}$, which was postmetalated in a second step with $\mathrm{Co}^{2+}, \mathrm{Mn}^{3+}, \mathrm{Cu}^{2+}$, and $\mathrm{Zn}^{2+}$ ions to give the corresponding COF-salen-M. For the COF-salen-M series once more a good agreement of an NLDFT calculated poresize distribution maximum $(1.86 \mathrm{~nm})$ with that from the model (calculated pore diameter $=1.9 \mathrm{~nm}$ ) was found when a fully eclipsed stacking of the 2D polymer sheets was assumed. ${ }^{113 b}$ The COF-salen-M series did not decompose in a broad $\mathrm{pH}$ range (from $1 \mathrm{M} \mathrm{HCl}$ to $1 \mathrm{M} \mathrm{NaOH}$ 

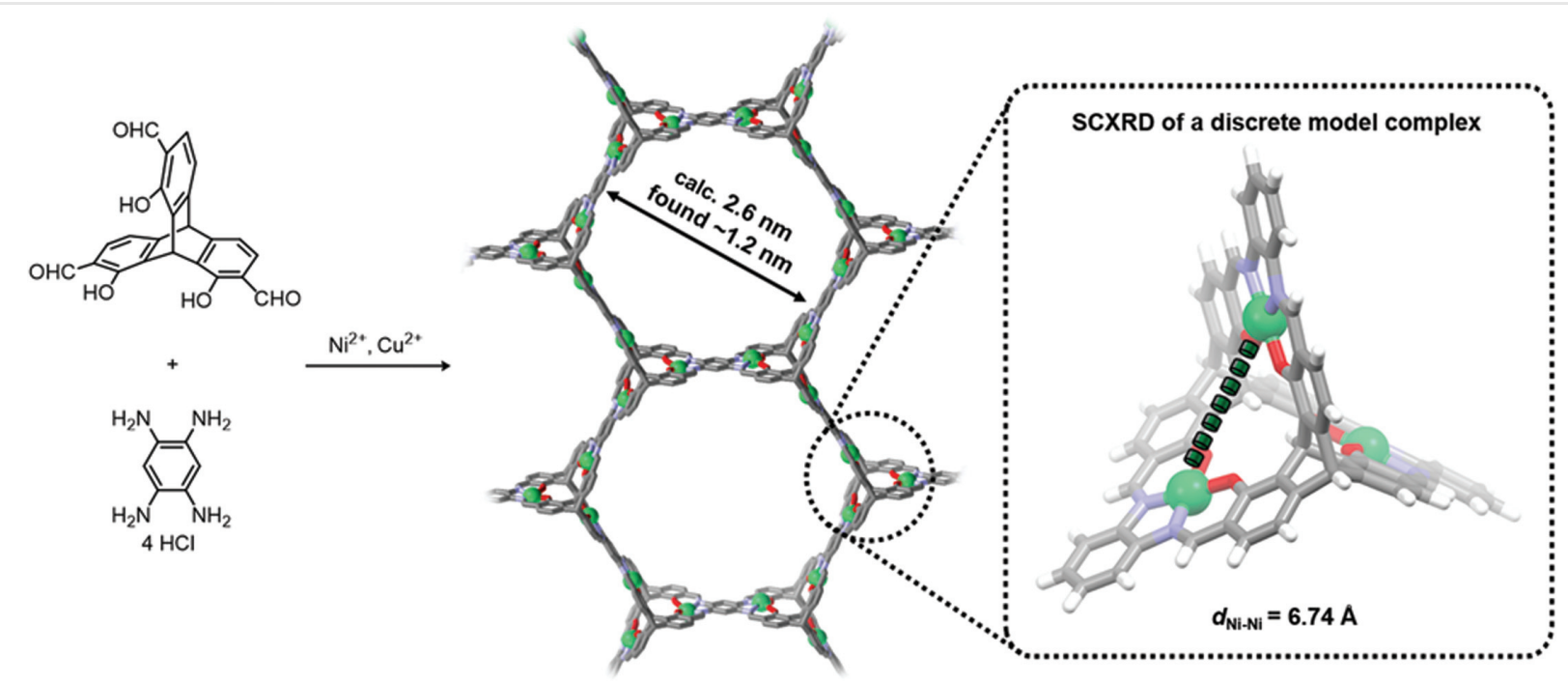

$\mathrm{M}_{3}$-MaSOFs

Scheme 11 Synthesis and structural representation of the $\mathbf{M}_{\mathbf{3}}$-MaSOF series. Box: single-crystal X-ray structure of a trinuclear nickel model complex with a metal-to-metal distance of $6.74 \AA$ A. (Parts of the scheme are adapted with permission from Ref. 115. Copyright $\odot 2019$ American Chemical Society.)

solutions) as proven by PXRD analyses of the immersed COF samples.

As it has been mentioned above, the sheets of the 2D salphen and salen COFs pack in an eclipsed fashion, thus in theory making the metal centers inaccessible for substrates of any kind. To avoid such a packing in combination with an ideal close arrangement of salphen metal centers, we synthesized $\mathrm{Ni}_{3}$ - and $\mathrm{Cu}_{3}$-MaSOFs (Scheme 11$)^{115}$ based on a triptycene trissalicylaldehyde. ${ }^{116}$ Indeed, by single-crystal X-ray diffraction (SCXRD) structure analyses of discrete trinuclear model complexes (Scheme 11, right), metal-to-metal distances of $d_{\mathrm{M}-\mathrm{M}}=6.7 \AA$ were found, which according to Zhang should be ideal to bind $\mathrm{CO}_{2}$ synergically. ${ }^{117}$ Unfortunately, the corresponding polymers $\mathrm{Ni}_{3}$ - and $\mathrm{Cu}_{3}-\mathrm{MaSOF}$ did not give any crystalline material with honeycomb $2 \mathrm{D}$-sheets but were rather amorphous (Scheme 11). The absence of highly ordered pores was also confirmed by the QSDFT (quenched solid DFT) pore-size analysis revealing that with 1.1-1.2 nm these are nearly half in size of what would have been expected for the idealized structure. Nevertheless, IR comparison of the MaSOFs with their molecular model compounds suggested the existence of well-defined trinuclear units within the polymers causing a high affinity towards $\mathrm{CO}_{2}$, which will be discussed below.

Similar to $1 \mathrm{D}$ polysalphens, 2D polysalphens have also been synthesized by palladium-catalyzed cross-coupling reactions. ${ }^{118}$ Surprisingly, despite the large toolbox of different coupling reactions as well as an unlimited stock of molecular building blocks, to the best of our knowledge, exclusively the Sonogashira-Hagihara cross-coupling of 1,3,5-triethynylbenzene with halogenated salens or salphens has been used for this purpose so far (Scheme 12). ${ }^{118}$ The polymers were permanently porous and mainly used in heterogeneous catalysis as discussed below.

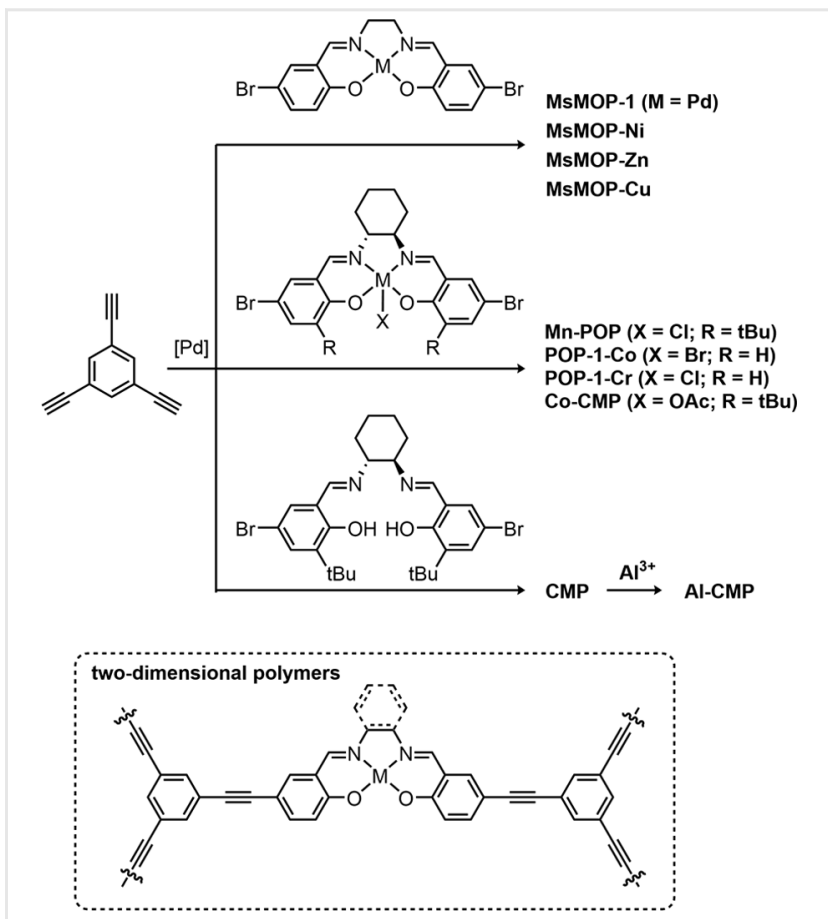

Scheme 12 Overview of 2D salen- and salphen-containing organic polymers made by Sonogashira-Hagihara cross-coupling reactions. Box: cut-out of the connecting unit. ${ }^{118}$ 
2D salen and salphen polymers were also obtained by radical polymerizations of vinyl- or allyl-substituted salphens ${ }^{119}$ and interfacial polymerization ${ }^{120}$ by crosslinking of linearly connected polymer chains. These polymers were of amorphous nature and have been used for the catalytic decomposition of $\mathrm{H}_{2} \mathrm{O}_{2}$ as in the case of Gupta's N,N-BSPDA-based beads (see discussion below) as well as the activation of molecular oxygen in the aerobic oxidation of cumene. ${ }^{120}$

\section{D-Salen and Salphen Polymers}

The majority of all COF structures are based on 2Dsheets and a much smaller proportion of COFs is threedimensional. ${ }^{121}$ Therefore, it is not surprising that only a few 3D polysalphens have been reported till date. In 2012 Mastalerz synthesized the first 3D salphen frameworks by the condensation of a tetraphenylmethane tetrakis-salicylaldehyde ${ }^{122}$ and 1,2-phenylene diamine in the presence of $\mathrm{Ni}(\mathrm{II})$ - or $\mathrm{Zn}(\mathrm{II})$-acetate (Scheme 13$).{ }^{123}$ The resulting

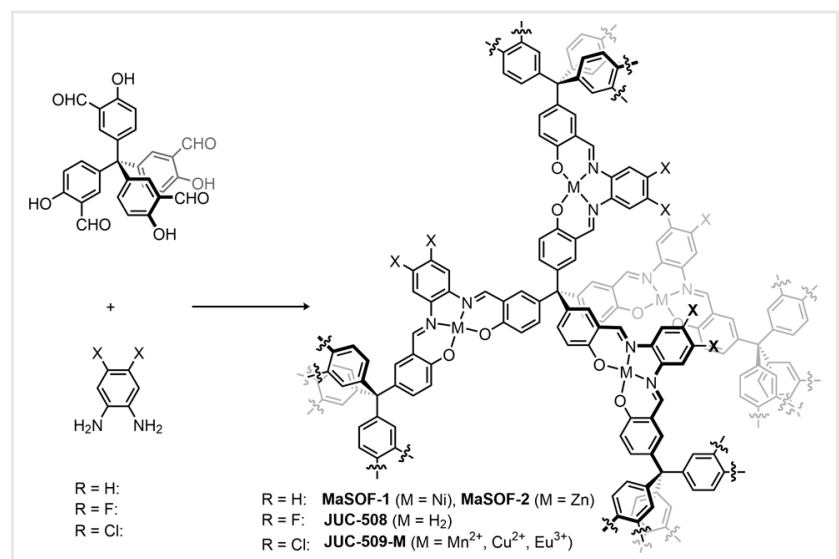

Scheme 13 Syntheses and structural motifs of Mastalerz's MaSOF-1 and -2 , as well as Fang's JUC-508, JUC-509, and the corresponding metalated networks. ${ }^{123,124}$

MaSOFs were analyzed by IR as well as ${ }^{13} \mathrm{C}$-CP-MAS spectroscopy, suggesting a high degree of polymerization because nearly no remaining aldehyde moieties were detected. Despite their amorphous nature, both MaSOFs were isostructural in pore size $(4.2 \AA)$ and specific surface areas $\left(\mathrm{SA}_{\mathrm{BET}}=630-647 \mathrm{~m}^{2} / \mathrm{g}\right)$ (see discussion below).

In 2019, Fang and coworkers reacted halogenated orthophenylene diamines with Mastalerz's tetraphenylmethanebased tetrakis-salicylaldehyde under solvothermal conditions and obtained the highly crystalline COFs JUC-508 $(\mathrm{Hal}=\mathrm{F})$ and JUC-509 $(\mathrm{Hal}=\mathrm{Cl})($ Scheme 13$) .{ }^{124}$ These networks retained their crystallinity after complexation with $\mathrm{Mn}^{2+}, \mathrm{Cu}^{2+}$, and $\mathrm{Eu}^{3+}$ ions. PXRD analyses in combination

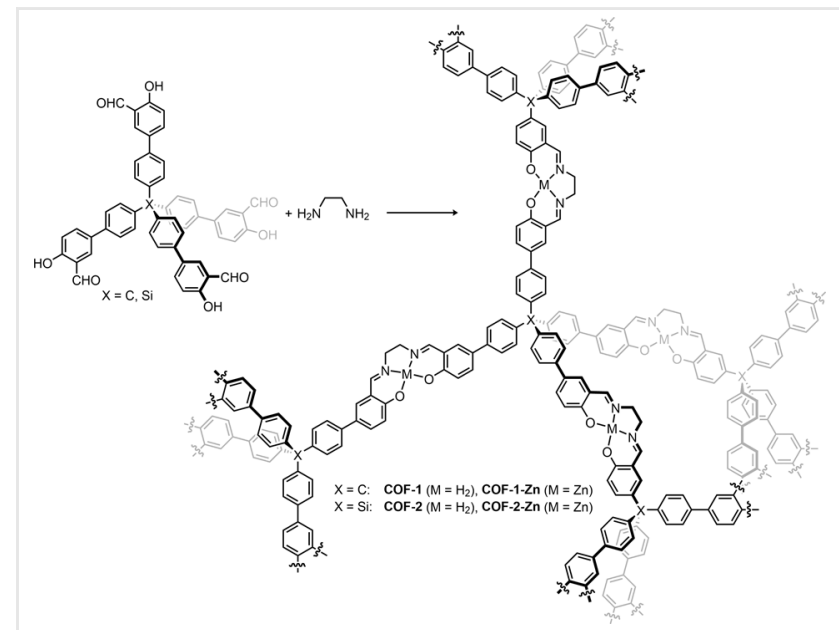

Scheme 14 Cui's COF-1, COF-2, COF-2-Zn, and COF-2-Zn. ${ }^{124}$

with modeling revealed for all COFs noninterpenetrated networks of a dia topology. ${ }^{124}$ When an extended tetraphenylmethane core with one more phenyl group ${ }^{122}$ or a siliconcentered analogue was used, sevenfold interpenetrated salphen COFs resulted, again with the dia topology (Scheme 14). ${ }^{125}$ In this case, an in-situ metalation upon condensation in addition to the postmetalation of presynthesized COFs gave networks with high degrees of crystallinity. ${ }^{125}$

It is worth mentioning that an inverse building block design was reported based on tetraaminotetraphenylmethane with a formyl-substituted Mn-salen (Scheme 15). ${ }^{126}$ The obtained materials showed gel-like behavior and have

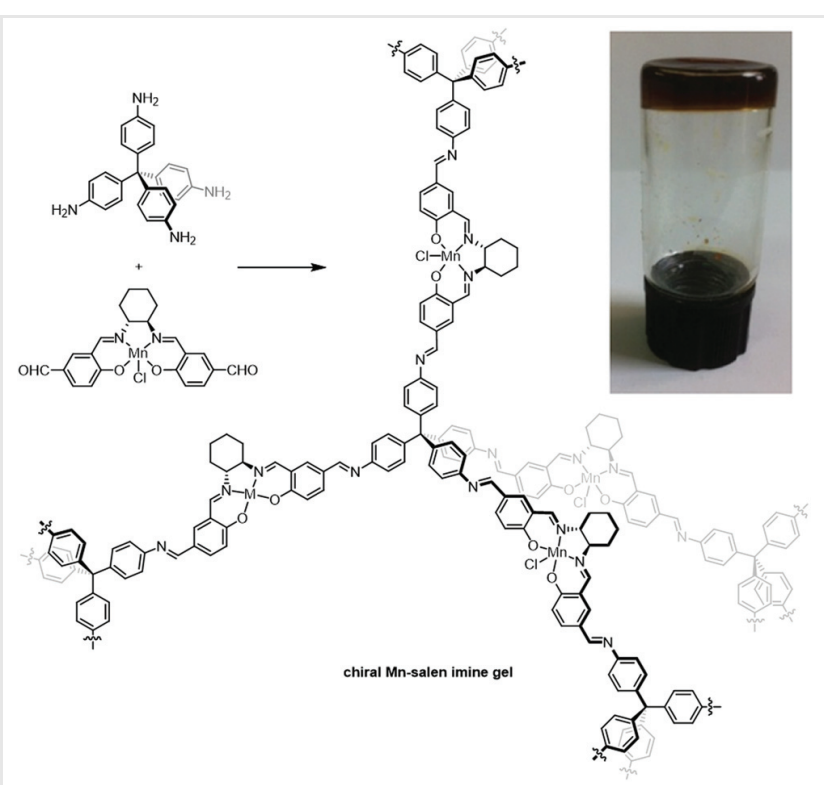

Scheme 15 Synthesis of a chiral Mn-salen imine gel. Inset: photograph of Mn-salen imine gel $\left(0.02 \mathrm{~mol} / \mathrm{L}\right.$ in DMSO). ${ }^{126}$ (Adapted with permission from Ref. 126. Copyright $\odot 2015$ The Royal Society of Chemistry.) 
been used in the asymmetric kinetic resolution of a racemic mixture of $R$ - and $S$-1-phenylethanol.

Similar to MaSOF- 1 and 2 as well as the $\mathrm{M}_{3}$-MaSOFs, the $\mathrm{M}-M a S O F_{50 / 100}$ series was synthesized via the imine condensation approach in the presence of the corresponding metal salts (Scheme 16). ${ }^{127}$ For this purpose, a triptycene-based hexakis-salicylaldehyde needed to be
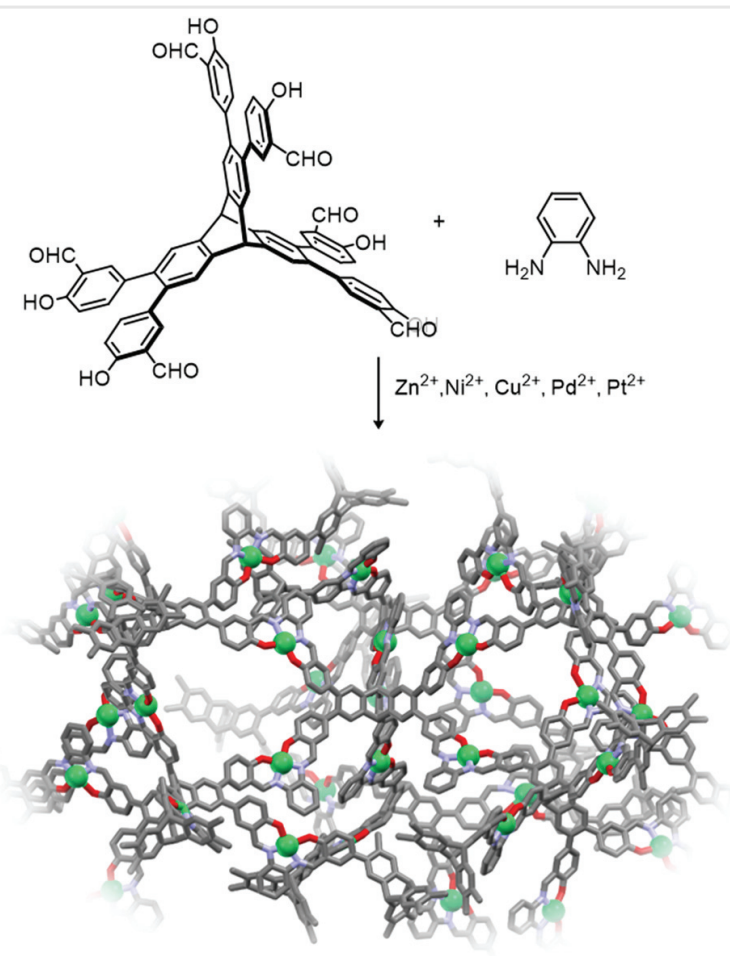

M-MaSOF $_{50 / 100}$

Scheme 16 Syntheses of MaSOF 50 and MaSOF 100 series. ${ }^{127}$

synthesized by a sequence of a sixfold Suzuki-Miyaura cross-coupling, a sixfold Duff formylation, and finally a sixfold demethylation. This hexakis-salicylaldehyde was used to synthesize a series of nearly isostructural MaSOFs with $\mathrm{Zn}(\mathrm{II}), \mathrm{Ni}(\mathrm{II}), \mathrm{Cu}(\mathrm{II}), \mathrm{Pd}(\mathrm{II})$, and Pt(II) metal centers. ${ }^{127}$ Independent from the reaction temperature, the $\mathrm{MaSOF}_{50}$ and $\mathrm{MaSOF}_{100}$ series showed comparable narrow pore-size distributions with micropores of $0.55-0.59 \mathrm{~nm}$ in diameter.

Besides the polymers obtained by imine condensations, the Sonogashira-Hagihara cross-coupling of tetrakis(4-ethynylphenyl)methane with different halogenated salen complexes was also used to synthesize 3D polymers. In 2013, the Son group synthesized the first 3D $\mathrm{Cr}^{3+}$ - and $\mathrm{Al}^{3+}$-salen networks (M-MON series) by cross-coupling methods of tetra (4-ethynylphenyl)methane with trans-cyclohexyldiaminebased diiodo-salens (Scheme 17). ${ }^{128}$ The insoluble polymers were investigated by ${ }^{13} \mathrm{C}-\mathrm{MAS}-\mathrm{NMR}$ as well as $\mathrm{X}$-ray photoelectron spectroscopy and PXRD, revealing their

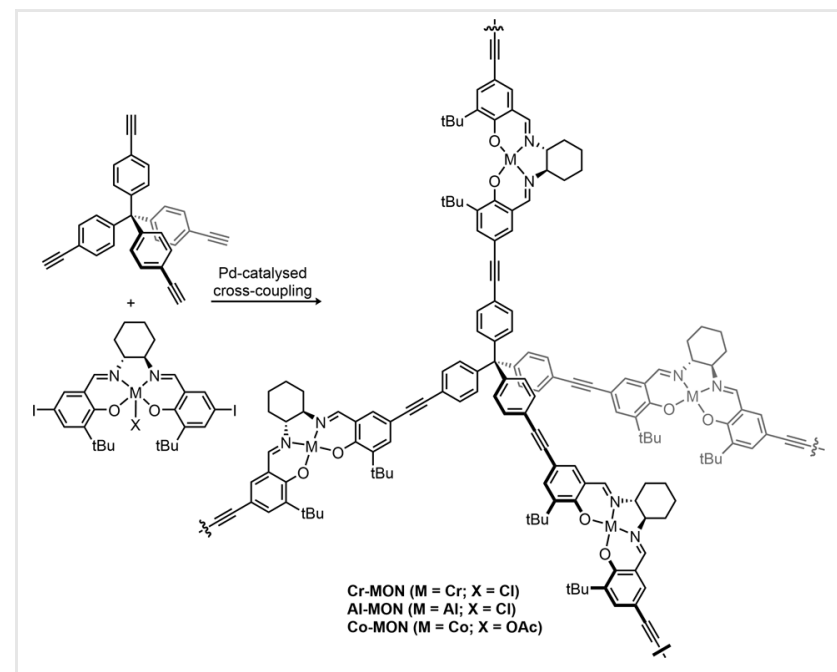

Scheme 17 Syntheses of 3D salen- and salphen-containing organic polymers by Sonogashira-Hagihara cross-coupling reactions. ${ }^{128}$

amorphous nature due to the irreversibility of the crosscoupling conditions. In accordance with their 2D-analogues, the M-MON series possess permanent porosity and were used as heterogeneous catalysts (see discussed below).

\section{Material Properties and Applications}

Depending on the molecular structure, the dimensionality, and the nature of the metal centers of the salen and salphens units, different materials properties result that lead to certain potential applications, which are discussed within the next section.

\section{Conductive Films}

Salen or salphen films prepared by electropolymerization commonly find application as conductive materials. One of the first examples was presented by Dahm and Peters in 1994 (Scheme 3). ${ }^{93 a}$ In this study, the catalytic reductions of iodoethane and 2-iodopropane to the corresponding ethyl- and 2-propyl radicals by the polysalphen films were studied and the mixture of subsequent products (different alkanes and the corresponding alkenes) was investigated. A comparison of the product distributions of the nickel(II)salen coated electrode with those of an uncoated one revealed that the film-coated electrodes exclusively generate products through a radical mechanism while the reaction on the uncoated electrode occurs via a cationic mechanism, demonstrating the significance of the salen polymer film in such transformations. ${ }^{93 a}$

In several studies the potential applications of salen or salphen/MWCNT composite materials as supercapacitors 
have been investigated. A direct relationship of the polysalen/MWCNT-ratio and the capacity of the resulting material was found, ${ }^{98 \mathrm{c}}$ and optimized films possessed between 3.8 and 8 times higher capacities compared to uncoated MWCNTs ${ }^{98 a, 99 a}$ with specific capacitances of up to $C=200 \mathrm{~F} / \mathrm{g}$ for a poly-Ni(II)salphen coated as well as $C=150 \mathrm{~F} / \mathrm{g}$ for a poly-Ni(II)salen coated MWCNT electrode. ${ }^{99 \mathrm{~b}}$ The latter also gives insight into the modulation of the electronic properties upon incorporation of salen or salphen backbones into conductive polymers. This was nicely exploited, for example, with conductive crown-ether decorated $\mathrm{Ni}(\mathrm{II})$ - and $\mathrm{Cu}(\mathrm{II})$-salen films, which have been

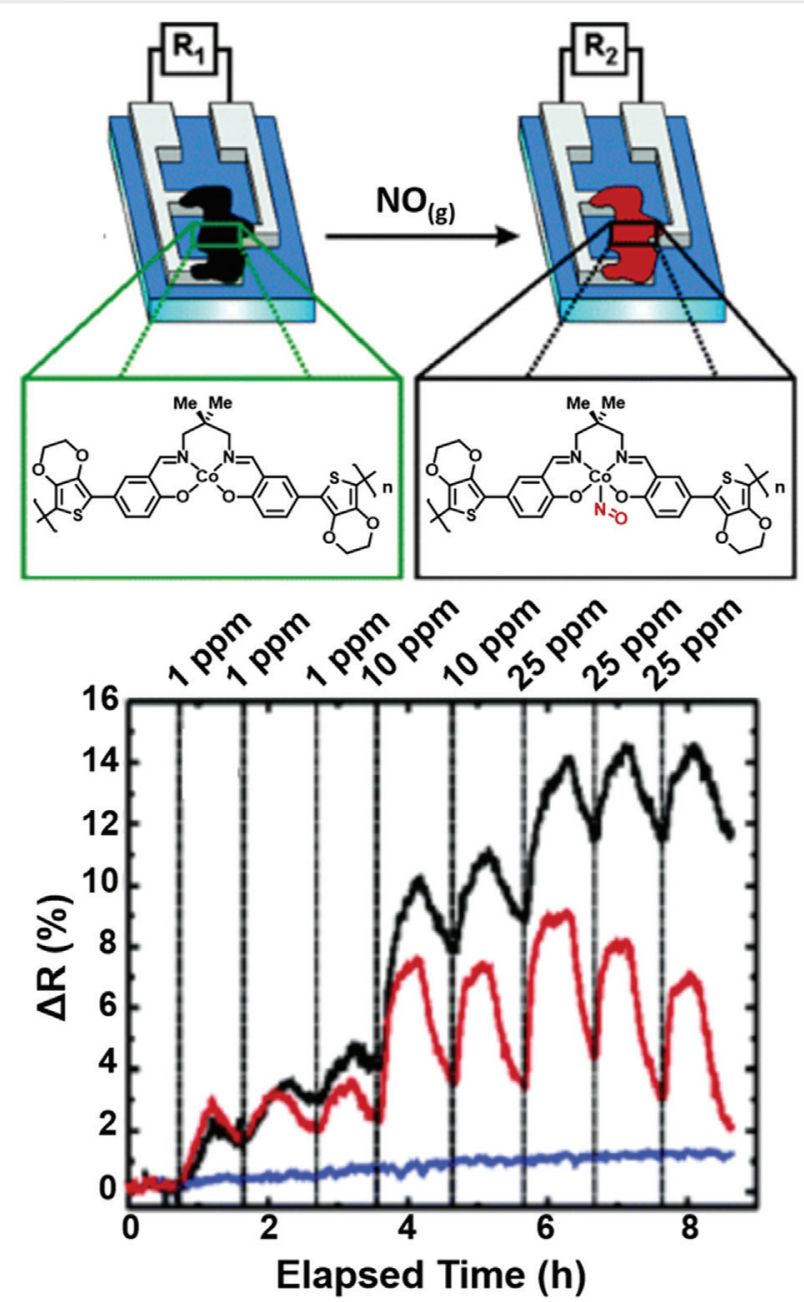

Figure 4 Top: schematic representation of interdigitated microelectrode array with an electropolymerized Co(III)-salen PEDOT copolymer as a sensor layer for $\mathrm{NO}$ sensing. Bottom: differential resistance $\left(R_{2} / R_{1}\right.$, see top figure) against time with various $\mathrm{NO}_{(\mathrm{g})}$ concentrations. Black: unconditioned poly-Co(III)-PEDOT film; red: conditioned (at $0.262 \mathrm{~V}$ ) poly-Co(III)-PEDOT film: blue: PEDOT film without salen moieties. ${ }^{97}$ (Adapted with permission from Ref. 97. Copyright (c) 2006 American Chemical Society.) used for molecular sensing of nanomolar amounts of metal ions $\left(\mathrm{Li}^{+}, \mathrm{Na}^{+}, \mathrm{Mg}^{2+}, \mathrm{Ba}^{2+}\right)$ and other nonionic species. ${ }^{94 \mathrm{~b}}$ In another study, nitric oxide $\left(\mathrm{NO}_{(\mathrm{g})}\right)$ was detected by a cobaltsalen-based PEDOT-substituted film. ${ }^{97}$ For this purpose, the as-mentioned cobalt-salen-based PEDOT polymers were electropolymerized onto an interdigitated microelectrode array (black in Figure 4, top) and the difference in the resistance $(\Delta R)$ between the parent sensor $\left(R_{1}\right)$ and the sensor under a stream of NO gas $\left(R_{2}\right)$ was evaluated (black and red curves in Figure 4 , bottom). The comparison to a similar setup with an electropolymerized PEDOT without salen units (blue curve, Figure 4, bottom) clearly indicated the role of the Co-salen moieties as the recognition sites of the sensor films. ${ }^{97}$

\section{Heterogeneous Catalysts}

The use of salens as well as salphens in homogenous catalysis inevitably led to the development of polymeric salens or salphens as heterogeneous catalysts. As early as in 1983, Wöhrle and coworkers demonstrated that a simple Co(II)-salen polymer can catalyze the valence isomerization of quadricyclane to norbornadiene, which has been proved to be superior for example to $\mathrm{Co}(\mathrm{II})$-porphyrin polymers (Scheme 18). ${ }^{129}$
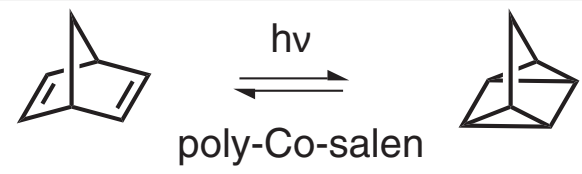

Scheme 18 Valence isomerization of norbornadiene to quadricyclane catalyzed by a $\mathrm{Co}(\mathrm{II})$ salen polymer. ${ }^{129}$

Gupta et al. constructed N,N-bis(3-allyl salicylidene)ophenylenediamine $(N, N$-BSPDA) based polymer beads (Scheme 19). It is worth mentioning that the polymer beads were among one of the first polymeric salphen materials with permanent porosity proven by gas sorption (Table 1). ${ }^{119 a}$ Depending on the cross-linker, specific surface areas up $380 \mathrm{~m}^{2} / \mathrm{g}$ have been obtained. After $\mathrm{Co}(\mathrm{II})$

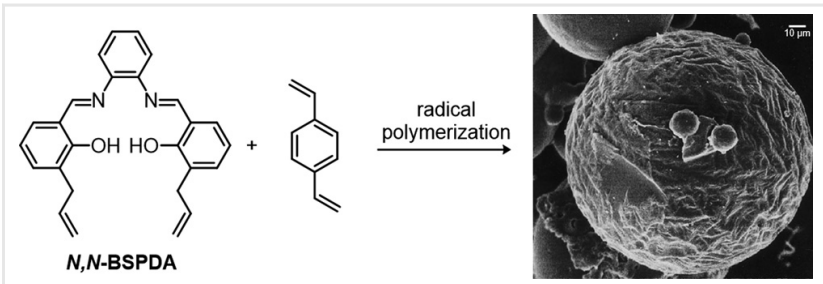

Scheme 19 Gupta's N,N-BSPDA-based beads by radical polymerization. Right: SEM micrograph of the corresponding bead after swelling. (Adapted with permission from Ref. 119a. Copyright $\odot 2003$ Elsevier Science B. V.) 
Table 1 Porous salen- and salphen-containing organic polymers used as heterogeneous catalysts

\begin{tabular}{|c|c|c|c|c|}
\hline Name & Metal & $\begin{array}{l}\mathrm{SA}_{\mathrm{BET}}{ }^{\mathrm{a}} \\
{\left[\mathrm{m}^{2} / \mathrm{g}\right]}\end{array}$ & Catalytic reaction & $\begin{array}{l}\text { Yield [\%] } \\
\text { up to }{ }^{b}\end{array}$ \\
\hline JUC-509-Cu & $\mathrm{Cu}$ & 957 & Dismutation of $\mathrm{O}_{2}{ }^{--}$ & $100^{c}$ \\
\hline JUC-509-Mn & $\mathrm{Mn}$ & 1016 & Dismutation of $\mathrm{O}_{2}{ }^{--}$ & $\sim 50^{c}$ \\
\hline JUC-509-Eu & Eu & 942 & Dismutation of $\mathrm{O}_{2}{ }^{\cdot-}$ & $\sim 10^{c}$ \\
\hline CCOF-4-Mn & $\mathrm{Zn} / \mathrm{Mn}$ & 614 & $\begin{array}{l}\text { Asym. epoxidation } \\
\text { of alkenes }\end{array}$ & $\begin{array}{l}79^{d} \\
(97 \% e e)^{e}\end{array}$ \\
\hline CCOF-4-V & $\mathrm{Zn} / \mathrm{V}$ & 547 & $\begin{array}{l}\text { Asym. cyanation } \\
\text { of aldehydes }\end{array}$ & $\begin{array}{l}79^{d} \\
(94 \% e e)^{e}\end{array}$ \\
\hline CCOF-4-Co & $\mathrm{Zn} / \mathrm{Co}$ & 628 & $\begin{array}{l}\text { Asym. Diels-Alder } \\
\text { reaction }\end{array}$ & $\begin{array}{l}87^{d} \\
(96 \% e e)^{e}\end{array}$ \\
\hline CCOF-4-Fe & $\mathrm{Zn} / \mathrm{Fe}$ & 566 & $\begin{array}{l}\text { Asym. epoxidation } \\
\text { of alkenes }\end{array}$ & $\begin{array}{l}71^{d} \\
(92 \% e e)^{e}\end{array}$ \\
\hline CCOF-4-Cr & $\mathrm{Zn} / \mathrm{Cr}$ & 633 & $\begin{array}{l}\text { Asym. aminolysis } \\
\text { of trans-stilbenes }\end{array}$ & $\begin{array}{l}76^{d} \\
(86 \% e e)^{e}\end{array}$ \\
\hline CCOF-4-Cr-Mn & $\mathrm{Zn} / \mathrm{Cr} / \mathrm{Mn}$ & 616 & $\begin{array}{l}\text { Alkene epoxidation } \\
\text { with subsequent } \\
\text { epoxide aminolysis }\end{array}$ & $\begin{array}{l}84^{d} \\
(91 \% e e)^{e}\end{array}$ \\
\hline Co/Salen-COF & Co & 854 & Henry reaction & $92^{f}$ \\
\hline COF-salen-Co & Co & 1065 & $\mathrm{CO}_{2}$ addition to epoxides & $91^{\mathrm{d}}$ \\
\hline COF-salen-Co(III) & $\mathrm{Co}(\mathrm{III})$ & 836 & Epichlorohydrin hydration & $98^{\mathrm{d}}$ \\
\hline COF-salen-Mn & $\mathrm{Mn}$ & 961 & Styrene epoxidation & $74^{\mathrm{d}}$ \\
\hline COF-salen-Cu & $\mathrm{Cu}$ & 1258 & $\mathrm{CO}_{2}$ addition to epoxides & $20^{\mathrm{d}}$ \\
\hline COF-salen-Zn & $\mathrm{Zn}$ & 1032 & $\mathrm{CO}_{2}$ addition to epoxides & $90^{\mathrm{d}}$ \\
\hline MsMOP-1 & Pd & 554 & $\begin{array}{l}\text { Pd-catalyzed } \\
\text { cross-coupling reactions }\end{array}$ & $99^{d}$ \\
\hline Cr-MON & $\mathrm{Cr}$ & 522 & $\mathrm{CO}_{2}$ addition to epoxides & $66^{9}$ \\
\hline Al-MON & $\mathrm{Al}$ & 650 & $\mathrm{CO}_{2}$ addition to epoxides & $71^{9}$ \\
\hline Co-MON & Co & 580 & $\mathrm{CO}_{2}$ addition to epoxides & $94^{9}$ \\
\hline Co-CMP & Co & 965 & $\mathrm{CO}_{2}$ addition to epoxides & $81^{\mathrm{h}}$ \\
\hline Al-CMP & Al & 798 & $\mathrm{CO}_{2}$ addition to epoxides & $91^{\mathrm{h}}$ \\
\hline Mn-POP & $\mathrm{Mn}$ & 836 & Alkene epoxidation & $>99^{d}$ \\
\hline POP-1-Co & Co & 370 & $\mathrm{CO}_{2}$ addition to epoxides & $97^{9}$ \\
\hline POP-1-Cr & $\mathrm{Cr}$ & 732 & $\mathrm{CO}_{2}$ addition to epoxides & $98^{9}$ \\
\hline DVB@ISA & Al & 590 & $\mathrm{CO}_{2}$ addition to epoxides & $99^{d}$ \\
\hline Al-CPOP & Al & 136 & $\mathrm{CO}_{2}$ addition to epoxides & $>99^{d}$ \\
\hline Zn@SBMMP & $\mathrm{Zn}$ & 423 & $\mathrm{CO}_{2}$ addition to epoxides & $97^{f}$ \\
\hline $\begin{array}{l}N, N^{\prime} \text {-BSPDA } \\
\text { Bead Type I }\end{array}$ & - & 56 & $\mathrm{H}_{2} \mathrm{O}_{2}$ decomposition & - \\
\hline $\begin{array}{l}N, N^{\prime} \text {-BSPDA } \\
\text { Bead Type II }\end{array}$ & - & 72 & $\mathrm{H}_{2} \mathrm{O}_{2}$ decomposition & - \\
\hline $\begin{array}{l}N, N^{\prime}-\text { BSPDA } \\
\text { Bead Type III }\end{array}$ & - & 94 & $\mathrm{H}_{2} \mathrm{O}_{2}$ decomposition & - \\
\hline $\begin{array}{l}N, N^{\prime} \text {-BSPDA } \\
\text { Bead Type IV }\end{array}$ & - & 132 & $\mathrm{H}_{2} \mathrm{O}_{2}$ decomposition & - \\
\hline $\begin{array}{l}N, N^{\prime}-\text { BSPDA } \\
\text { Bead Type V }\end{array}$ & & 380 & $\mathrm{H}_{2} \mathrm{O}_{2}$ decomposition & - \\
\hline
\end{tabular}

Derived from $\mathrm{N}_{2}$ sorption experiments at $77 \mathrm{~K}$.

${ }^{b}$ For selected examples.

${ }^{c}$ Clearance rate.

Determined by GC analyses.

e Determined by HPLC analyses.

fIsolated yield based on benzaldehyde.

${ }^{9}$ Determined by ${ }^{1} \mathrm{H}$-NMR analyses.

hIsolated yield. complexation, the beads became catalytically active for the decomposition of $\mathrm{H}_{2} \mathrm{O}_{2}$. ${ }^{119 a}$

Mn-POP, a 2D salen polymer obtained via the abovedescribed Sonogashira-Hagihara approach (for the structure see discussion above; Scheme 12), was also permanently porous $\left(\mathrm{SA}_{\mathrm{BET}}=836 \mathrm{~m}^{2} / \mathrm{g}\right.$, Table 1$)$ and was capable to catalytically transfer olefins to the corresponding epoxides with conversions of up to 99\%, similar to Vancheesan's M(III) polysalphens (Scheme 20). ${ }^{118 \mathrm{~d}, 130}$

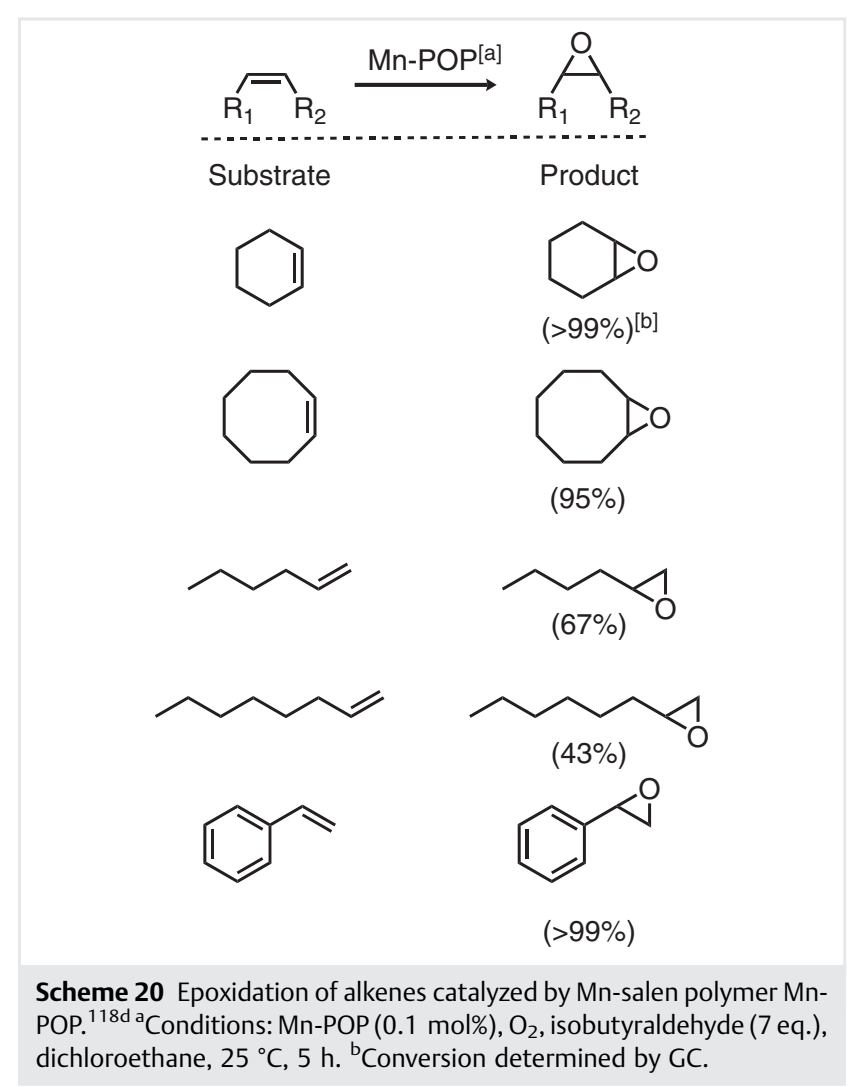

A large number of metal-salen and-salphen polymers have been used in the synthesis of cyclic carbonates from epoxides upon $\mathrm{CO}_{2}$ capture, as it is known from the corresponding discrete complexes. ${ }^{72 a, 128,131}$ The key advantage to their smaller congeners is their recyclability as a heterogeneous catalyst. ${ }^{110 a, 118 e, 119 b, 132}$ For example, Deng et al.'s CMP series (for the structure see discussion above; Scheme 12) was able to be used for cyclic carbonate formations in up to 22 cycles even under ambient conditions. ${ }^{118 \mathrm{~b}}$

Polymers such as POP-1-Cr $\left(\mathrm{SA}_{\mathrm{BET}}=732 \mathrm{~m}^{2} / \mathrm{g}\right),{ }^{118 \mathrm{e}} \mathrm{POP}-1$ Co $\left(\mathrm{SA}_{\mathrm{BET}}=370 \mathrm{~m}^{2} / \mathrm{g}\right){ }^{118 \mathrm{e}}$ Al-CPOP $\left(\mathrm{SA}_{\mathrm{BET}}=136 \mathrm{~m}^{2} / \mathrm{g}\right)^{132}$ or Co- $\left(\mathrm{SA}_{\mathrm{BET}}=580 \mathrm{~m}^{2} / \mathrm{g}\right){ }^{118 \mathrm{~b}}$ and Al-CMP $\left(\mathrm{SA}_{\mathrm{BET}}=798\right.$ $\left.\mathrm{m}^{2} / \mathrm{g}\right)^{118 \mathrm{~b}}$ possess permanent porosity as indicated by nitrogen sorption (see discussion below; Table 1). High turnover frequencies (TOF) of up to $1875 \mathrm{~h}^{-1113 \mathrm{~b}}$ and turnover numbers (TONs) of over 200 have been achieved for 
example in addition reactions of $\mathrm{CO}_{2}$ to epoxides. ${ }^{133}$ The highest TONs (496) were achieved with an ionic ammonium polymer bearing salen $\mathrm{Co}(\mathrm{III})$-salens ${ }^{110 \mathrm{~b}}$ or with POP-1$\mathrm{Cr}(693) .{ }^{118 \mathrm{e}}$

One interesting approach to capture $\mathrm{CO}_{2}$ that is different from the one described above is realized with ionic $\mathrm{Zn}$ (II)salen polymer DVB@ISZ, which converts the $\mathrm{CO}_{2}$ to synthetically more valuable formamides in high yields of up to $99 \%$ from amines using $\mathrm{PhSiH}_{3}$ as an in-situ reductant (Scheme 21). ${ }^{110 c}$ The high reactivity was attributed to the

$$
\begin{gathered}
\mathrm{CO}_{2} \text { capture as cyclic carbonate } \\
\text { POP-1-Cr/Co } \\
\text { Co/Al-CMP }
\end{gathered}
$$

$\mathrm{CO}_{2}$ capture as formamide

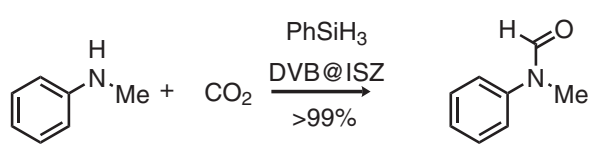

Scheme 21 Different methods to capture $\mathrm{CO}_{2} \cdot{ }^{110 \mathrm{c}}$

Lewis acidic nature of the $\mathrm{Zn}(\mathrm{II})$ centers in salen and salphen moieties, as has been reported for other $\mathrm{Zn}(\mathrm{II})$ salphens too. $^{72 a, 73 a, b, 78 a, 134}$

It is obvious that asymmetric transformations were realized by using chiral salen polymers. For example, Takata and coworkers reported the asymmetric addition of diethylzinc to aldehydes using a chiral helical $\mathrm{Zn}(\mathrm{II})-$ polysalen (structure in Scheme 5) in high enantiomeric excess (ee) of $95 \%$, while the use of the related enantiomerically pure mononuclear $\mathrm{Zn}$ (II) salphen resulted in a product with an ee of only $5 \%$ (Scheme 22). ${ }^{101 a, c}$

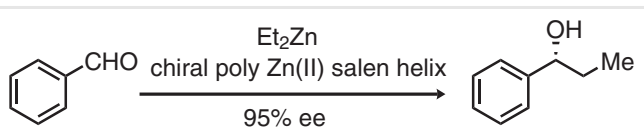

Scheme 22 Asymmetric addition of $\mathrm{Et}_{2} \mathrm{Zn}$ to aldehydes, catalyzed by Takata's poly $\mathrm{Zn}(\mathrm{II})$ salen helix. ${ }^{101 a, 101 c}$

An isostructural chiral helical poly-Mn(III)-salen was used in the asymmetric epoxidation of styrenes, but only delivered a low selectivity of $17 \% e e,{ }^{101 b}$ which is higher than that for the homogenous pendant (1-6\% ee), but unfortunately lower than that of other chiral salen complexes (ee up to $98 \%$ ). ${ }^{135}$ This was improved in 2005 by Gothelf and coworkers using also chiral $\mathrm{Mn}(\mathrm{III})$ salen polymers (structure in Scheme 9; see above), but this time chirality was introduced by enantiomerically pure diamines. ${ }^{111}$ The transformation of cis-methyl styrene was performed with a cis/trans-ratio of $12: 1$ and an ee of $67 \%$.
The epoxidation by porous salphen polymers was further improved by Cui and coworkers in $2017 .{ }^{113 a}$ The porous $\mathrm{Mn}$ (III)- (CCOF-4-Mn; $\mathrm{SA}_{\mathrm{BET}}=614 \mathrm{~m}^{2} / \mathrm{g}$ ) alongside the Fe(III)salen polymers (CCOF-4-Fe; $\mathrm{SA}_{\mathrm{BET}}=566 \mathrm{~m}^{2} / \mathrm{g}$; for structures, see Scheme 10) were able to convert 2,2-dimethyl$2 \mathrm{H}$-chromene with iodosylbenzene (or derivatives thereof) as an oxidant to the corresponding epoxides with up to $97 \%$ ee (Scheme 23). ${ }^{113 a}$ In this publication, the full potential of embedding different metal ions into the pockets of salens
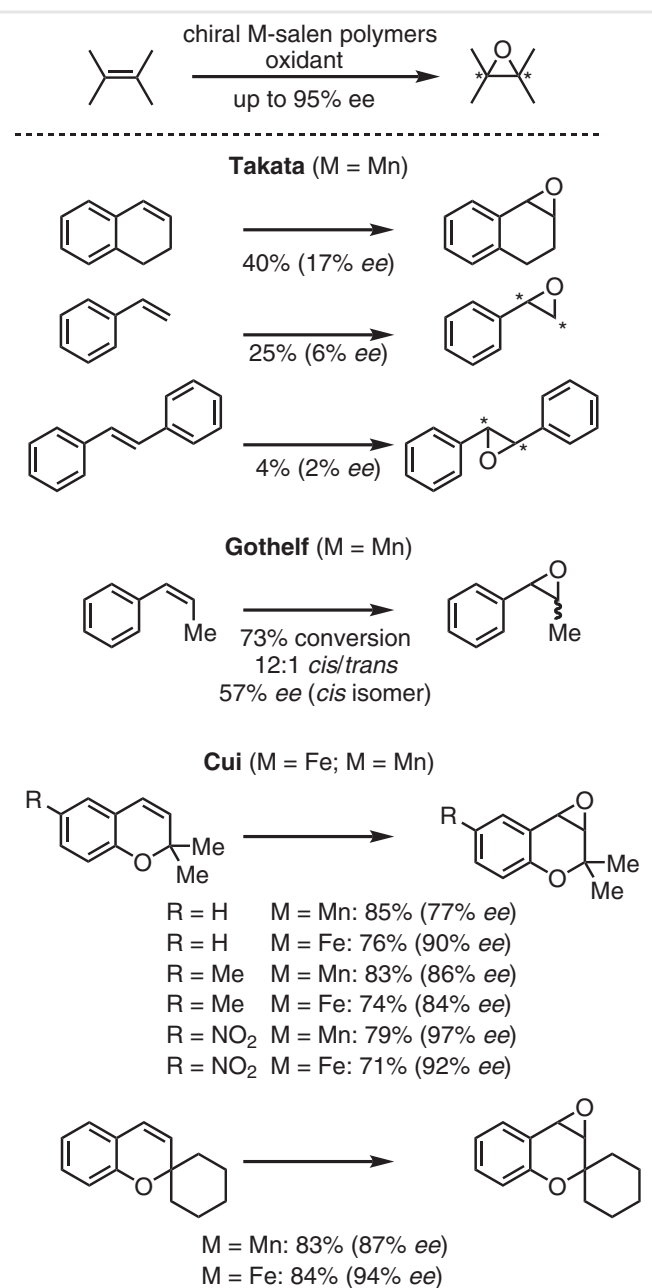

Scheme 23 Asymmetric epoxidation of styrenes catalyzed by various poly M-salens (for synthesis and structures of the corresponding polymers, see Scheme $5,{ }^{101 b}$ Scheme $9,{ }^{111}$ and Scheme 10). ${ }^{113 a}$

(here CCOF-4-M) for different reactions was demonstrated. For instance, other asymmetric transformations were achieved with high yields and high ee values, such as the cyanosilylation of aldehydes ( $\mathrm{M}=\mathrm{V}$; up to $94 \%$ ee), DielsAlder reactions of 1-amino-substituted butadienes and $\alpha$ amino acroleins ( $\mathrm{M}=\mathrm{Co}$; up to $96 \% e e)$, aminolysis of transstilbene oxide with anilines $(\mathrm{M}=\mathrm{Cr}$; up to $96 \% e e)$, or epoxidation of alkenes followed by a subsequent ring 


$$
\text { cyanosilylation of aldehydes }
$$<smiles>O=Cc1ccc(Br)cc1</smiles>
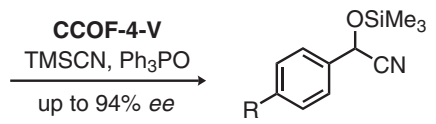

$\mathrm{R}=\mathrm{Me}, \mathrm{OMe}, \mathrm{Br}$

Diels-Alder reaction of 1-amino butadienes with $\alpha$-substituted acroleins

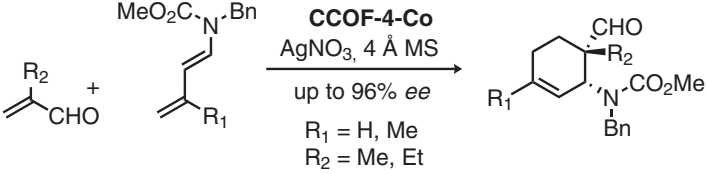

aminolysis of trans-stilbene oxide

$$
\text { up to 96\% ee }
$$

epoxidation with subsequent ring opening

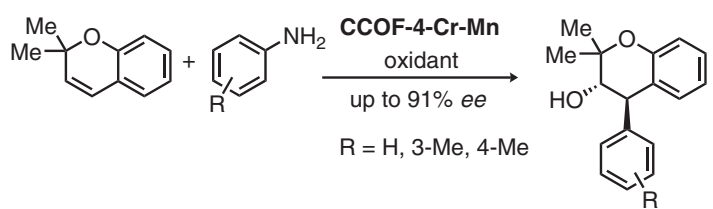

Scheme 24 Asymmetric transformations catalyzed by different members of Cui's CCOF-4-M series (for synthesis and structures, see Scheme 10). ${ }^{113 a}$

opening in the presence of anilines to obtain amino alcohols ( $\mathrm{M}=\mathrm{Cr}$, Mn; up to $91 \%$ ee) (Scheme 24 ).

All polymers were porous ( $S A_{\mathrm{BET}}$ up to $683 \mathrm{~m}^{2} / \mathrm{g}$, Table 1 ) and their reusability was exemplarily proven for the cyanation reaction: no leaching of metal ions was detected by ICP-OES and the crystallinity remained even after five runs as investigated by PXRD. ${ }^{113 a}$

Other examples are $\mathrm{Co}(\mathrm{III})$-salen polymers catalyzing the Henry reaction of substituted benzaldehydes and nitromethane $^{112}$ or the hydration of epichlorohydrin (EPH). ${ }^{113 b}$

Interestingly, Pd(II)-salen polymers have been reported to catalyze cross-coupling reactions such as SuzukiMiyaura reactions of various arylhalides with phenylboronic acid or Heck reactions of arylhalides with styrene or ethyl acrylate in yields up to $99 \%{ }^{118 a}$ This rare and unusual use of metal salphens in $\mathrm{C}-\mathrm{C}$ cross-coupling reactions ${ }^{136}$ underlines that the broad potential of porous polymetal-salphens still needs to be explored.

\section{Porous Materials for Gas Sorption and Separation}

Most of the above-discussed catalytically active metal salen or salphen polymers are permanently porous, with high surface areas, which is favorable to provide accessible catalytic centers. The data of nitrogen sorption experiments of these salen and salphen polymers are summarized in Table 1. Among the metal-containing porous salen and salphen polymers, Yang's COF-salen-Cu (see above; Scheme 10) that was used for catalytic $\mathrm{CO}_{2}$ fixation and the corresponding metal-free COF-salen precursor have with $\mathrm{SA}_{\mathrm{BET}}=1,258$ and $1,646 \mathrm{~m}^{2} / \mathrm{g}$, respectively, the highest reported specific surface areas of all here-discussed polymers (Scheme 24). ${ }^{113 \mathrm{~b}}$ Besides for heterogeneous catalysis, porous salphen and salen polymers were investigated for gas sorption and separation.

As discussed above, Mastalerz et al. reported 3D porous networks based on a tetraphenylmethane unit as the building block in 2012 (structure in Scheme 13). The resulting porous salphen polymers were named MaSOF-1 $\left(\mathrm{M}=\mathrm{Ni}(\mathrm{II}), \mathrm{SA}_{\mathrm{BET}}=647 \mathrm{~m}^{2} / \mathrm{g}\right)$ and MaSOF-2 $(\mathrm{M}=\mathrm{Zn}(\mathrm{II})$, $\mathrm{SA}_{\mathrm{BET}}=630 \mathrm{~m}^{2} / \mathrm{g}$; Table 2). ${ }^{123}$ Both MaSOFs adsorbed comparable amounts of $\mathrm{H}_{2}$ at $77 \mathrm{~K}$ and 1 bar $(4.46 \mathrm{mmol} / \mathrm{g}$, $0.90 \mathrm{wt} . \%$ and $4.14 \mathrm{mmol} / \mathrm{g}, 0.90 \mathrm{wt} . \%)$ but the zinccontaining MaSOF-2 showed a slightly higher uptake of $\mathrm{CO}_{2}(2.23 \mathrm{mmol} / \mathrm{g}, 9.8 \mathrm{wt} . \%)$ than the nickel analogue MaSOF-1 (1.83 mmol/g, $8.1 \mathrm{wt} . \%)$, which was attributed to the higher Lewis acidity of the incorporated zinc centers (Table 2). ${ }^{123}$

For some of the salphens used for $\mathrm{CO}_{2}$ fixation (see above), the corresponding volumetric uptakes of $\mathrm{CO}_{2}$ at 1 bar were determined before catalysis testing. Co- as well as Al-CMP for example takes up $1.80 \mathrm{mmol} / \mathrm{g}$ (7.93 wt.\%; Co$\mathrm{CMP}$ ) and $1.73 \mathrm{mmol} / \mathrm{g}$ (7.65 wt.\%; Al-CMP) at $298 \mathrm{~K}$, respectively (Table 2$).{ }^{118 \mathrm{~b}}$ Among those salphen polymers used for heterogeneous catalysis for $\mathrm{CO}_{2}$ addition on epoxides, Zn@SBMMP took up the highest amount of $\mathrm{CO}_{2}$ (2.14 mmol/g, $9.40 \mathrm{wt} . \%)$. This value is only outperformed by salphen networks designed for gas sorption (Table 2). ${ }^{118 c, 115,123,127}$ For example, one of the first porous MaSOFs, MaSOF-2, has already been reported to have an uptake of $2.23 \mathrm{mmol} / \mathrm{g}$ (9.8 wt.\%) of $\mathrm{CO}_{2}$ at $273 \mathrm{~K}$ and 1 bar. $^{123}$

In 2018 the Mastalerz group introduced the next generation of MaSOFs based on a triptycene hexakissalicylaldehyde. In combination with different metal sources, two isostructural series of compounds (M-MaSOF 50 and $\mathrm{M}-M a S O F_{100}$ ) with $\mathrm{M}=\mathrm{Zn}(\mathrm{II}), \mathrm{Cu}(\mathrm{II}), \mathrm{Ni}(\mathrm{II}), \mathrm{Pd}(\mathrm{II})$ as well as $\mathrm{Pt}(\mathrm{II})$ were synthesized at 50 and $100{ }^{\circ} \mathrm{C}$ (denoted by the suffix in the name). The BET surface areas measured by nitrogen sorption at $77 \mathrm{~K}$ (Figure 5) of all compounds range between 492 and $816 \mathrm{~m}^{2} / \mathrm{g}$. More importantly, all structures have pronounced and defined pores in the microporous regime with a diameter of approximately $5.7 \AA$ (Figure 5), thus making these compounds ideal to compare the influence of the metal centers on gas sorption and selectivity. Significantly higher $\mathrm{CO}_{2}$ uptakes were

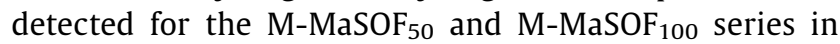
comparison to the MaSOFs 1 and -2 . For instance, Ni- 
Table 2 Comparison of porous salen- and salphen-containing organic polymers used for gas sorption and separation

\begin{tabular}{|c|c|c|c|c|c|c|}
\hline \multirow[t]{2}{*}{ Name } & \multirow[t]{2}{*}{ Metal } & \multirow{2}{*}{$\begin{array}{l}\mathrm{SA}_{\mathrm{BEEE}}^{\mathrm{a}} \\
{\left[\mathrm{m}^{2} / \mathrm{g}\right]}\end{array}$} & \multirow{2}{*}{$\begin{array}{l}\mathrm{CO}_{2} \text { uptake }^{\mathrm{b}} \\
{[\mathrm{mmol} / \mathrm{g}]} \\
\text { (wt.\%) }\end{array}$} & \multicolumn{2}{|c|}{ IAST selectivity } & \multirow[t]{2}{*}{ Ref. } \\
\hline & & & & $\mathrm{CO}_{2} / \mathrm{CH}_{4}{ }^{\mathrm{c}}$ & $\mathrm{CO}_{2} / \mathrm{N}_{2}{ }^{\mathrm{d}}$ & \\
\hline MaSOF-1 & $\mathrm{Ni}$ & 647 & $1.83(8.05)$ & $-^{e}$ & - & 123 \\
\hline Masof-2 & $\mathrm{Zn}$ & 630 & $2.23(9.81)$ & - & - & 123 \\
\hline $\mathrm{Zn}-\mathrm{MaSOF}_{100}$ & $\mathrm{Zn}$ & 638 & $4.28(13.6)$ & 10 & 48 & 27 \\
\hline $\mathrm{Zn}-\mathrm{MaSOF}_{50}$ & $\mathrm{Zn}$ & 540 & $4.02(12.8)$ & 9.5 & 45 & 27 \\
\hline $\mathrm{Ni}^{\mathrm{MaSOF}}{ }_{100}$ & $\mathrm{Ni}$ & 816 & $4.83(15.6)$ & 9.0 & 42 & 127 \\
\hline $\mathrm{Ni}-\mathrm{MaSOF}_{50}$ & $\mathrm{Ni}$ & 754 & 4.48 (14.5) & 8.8 & 44 & 127 \\
\hline $\mathrm{Cu}^{\mathrm{M}} \mathrm{MaSOF}_{100}$ & $\mathrm{Cu}$ & 697 & $4.66(14.9)$ & 10.3 & 52 & 127 \\
\hline${\mathrm{Cu}-\mathrm{MaSOF}_{50}}$ & $\mathrm{Cu}$ & 725 & $4.72(15.1)$ & 9.9 & 50 & 127 \\
\hline Pd-MaSOF $_{100}$ & $\mathrm{Pd}$ & 511 & $4.11(12.0)$ & 10.5 & 56 & 127 \\
\hline $\mathrm{Pd}^{-\mathrm{MaSOF}_{50}}$ & $\mathrm{Pd}$ & 575 & $4.24(12.4)$ & 8.7 & 43 & 127 \\
\hline Pt-MaSOF $_{100}$ & $\mathrm{Pt}$ & 572 & $4.39(10.9)$ & 9.5 & 86 & 127 \\
\hline Pt-MaSOF 50 & $\mathrm{Pt}$ & 492 & $4.09(10.2)$ & 9.5 & 48 & 27 \\
\hline $\mathrm{H}_{2}-\mathrm{SOF}$ & - & 116 & $2.12(7.84)$ & 10.5 & 32 & 27 \\
\hline $\mathrm{Ni}_{3}-\mathrm{MaSOF}_{\text {as }}$ & $\mathrm{Ni}$ & 373 & $2.36(10.4)$ & 16 & 89 & 115 \\
\hline $\mathrm{Ni}_{3}-\mathrm{MaSOF}_{\mathrm{w}}$ & $\mathrm{Ni}$ & 441 & $2.45(10.8)$ & 11 & 64 & 115 \\
\hline $\mathrm{Cu}_{3}-\mathrm{MaSOF}_{\text {as }}$ & $\mathrm{Cu}$ & 625 & 3.39 (14.9) & 12 & 69 & 115 \\
\hline $\mathrm{Cu}_{3}-\mathrm{MaSOF}_{\mathrm{w}}$ & $\mathrm{Cu}$ & 890 & $5.02(22.1)$ & 9 & 40 & 115 \\
\hline MsMOP-Ni & $\mathrm{Ni}$ & 1087 & $1.85(8.15)$ & - & $46^{f}$ & $18 \mathrm{c}$ \\
\hline MsMOP-Zn & $\mathrm{Zn}$ & 785 & $1.17(5.16)$ & - & $31^{f}$ & $118 c$ \\
\hline MsMOP-Pt & Pt & 1202 & $1.67(7.33)$ & - & $20^{f}$ & $118 \mathrm{c}$ \\
\hline CMP & - & 772 & $1.61(7.10)$ & - & - & $118 \mathrm{t}$ \\
\hline $\mathrm{Al}-\mathrm{CMP}$ & Al & 798 & $1.73(7.65)$ & - & - & $18 \mathrm{t}$ \\
\hline Co-CMP & Co & 965 & $1.80(7.93)$ & - & - & $18 \mathrm{t}$ \\
\hline DVB@ISA & $\mathrm{Al}$ & 590 & $1.14(5.04)$ & - & - & $110 c$ \\
\hline Al-CPOP & Al & 136 & $0.54(2.36)^{9}$ & - & - & 132 \\
\hline Zn@SBMMP & $\mathrm{Zn}$ & 423 & $2.14(9.40)$ & - & - & 133 \\
\hline
\end{tabular}

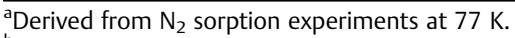

${ }^{\mathrm{b}} \mathrm{At} 273 \mathrm{~K}$ and 1 bar.

${ }^{c}$ For a 50:50 mixture at $273 \mathrm{~K}$ and $0.1 \mathrm{bar}$.

${ }^{d}$ For a $20: 80$ mixture at $273 \mathrm{~K}$ and 0.1 bar.

e Not determined.

fIdeal selectivity.

${ }^{9}$ At $298 \mathrm{~K}$ and 1 bar.

$\mathrm{MaSOF}_{100}$ adsorbs the highest amount of $\mathrm{CO}_{2}$ (4.83 $\mathrm{mmol} / \mathrm{g}, 15.6 \mathrm{wt} . \%$ ) at $273 \mathrm{~K}$ and 1 bar (Figure 5 and Table 2) within this series. ${ }^{127}$ For all MaSOFs in these series, high Henry- and ideal adsorbed solution theory (IAST) selectivities of $\mathrm{CO}_{2}$ against $\mathrm{CH}_{4}$ or $\mathrm{N}_{2}$ were determined with Pt-MaSOF 100 having the highest selectivity for $\mathrm{CO}_{2} / \mathrm{N}_{2}$ of $S_{\text {IAST }}=86$ at 0.1 bar at $273 \mathrm{~K}^{127}$ This value is one of the highest reported for all polysalphens, higher than those found in the MsMOP-M series $\left(S_{\text {IDEAL }} \text { up to } 46\right)^{118 c}$ and only outperformed by $\mathrm{Ni}_{3}-\mathrm{MaSOF}_{\text {as }}\left(\mathrm{S}_{\text {IAST }}=89\left(\mathrm{CO}_{2} / \mathrm{N}_{2}\right)\right.$ at 0.1 bar; see also discussion below). ${ }^{115}$

The next evolutionary step in the construction of MaSOFs for gas sorption was the development of the $\mathrm{M}_{3}$ MaSOFs $(\mathrm{M}=\mathrm{Cu}$ and $\mathrm{Ni}) .{ }^{115}$ Based on previous results in

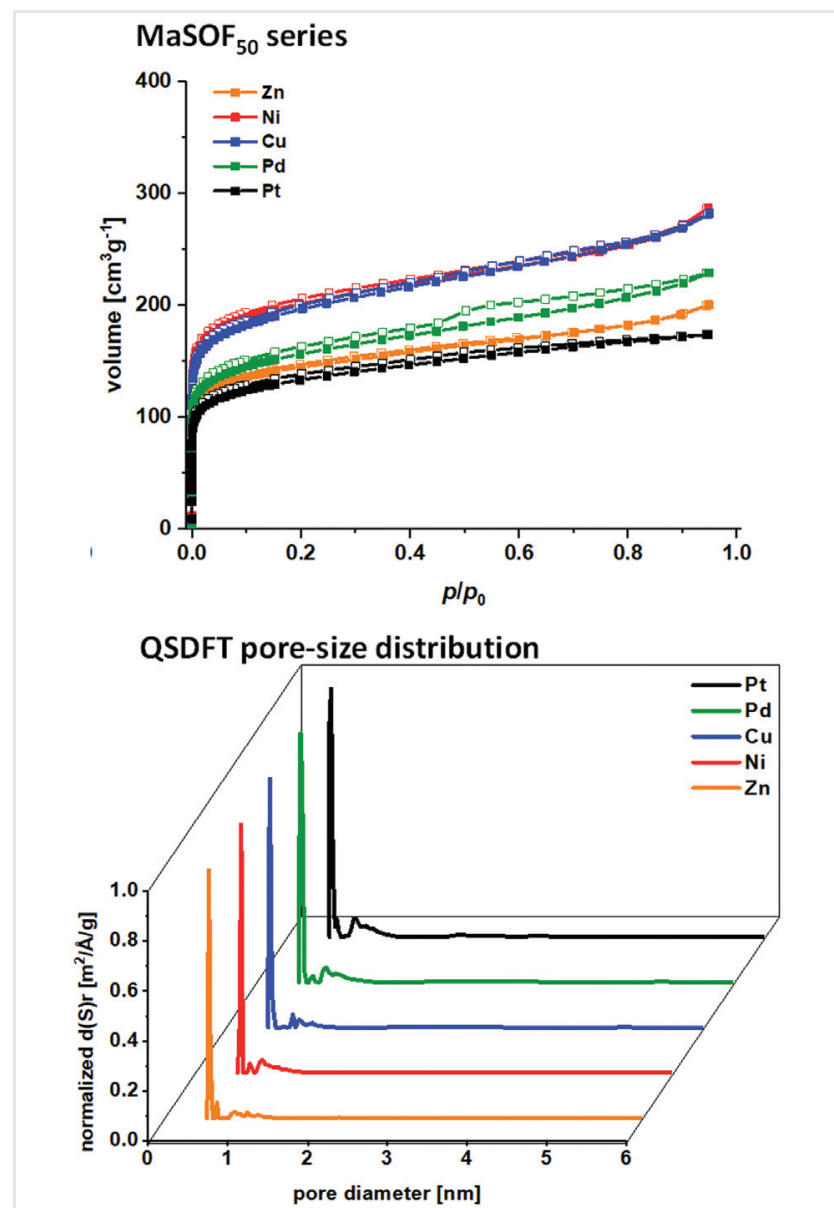

Figure 5 Top: nitrogen sorption isotherms $\left(77 \mathrm{~K}\right.$ ) of $\mathrm{MaSOF}_{50}$ series. Bottom: QSDFT pore-size distributions of the $\mathrm{MaSOF}_{50}$ series. ${ }^{127}$ (Adapted with permission from Ref. 127. Copyright @ 2018 American Chemical Society.)

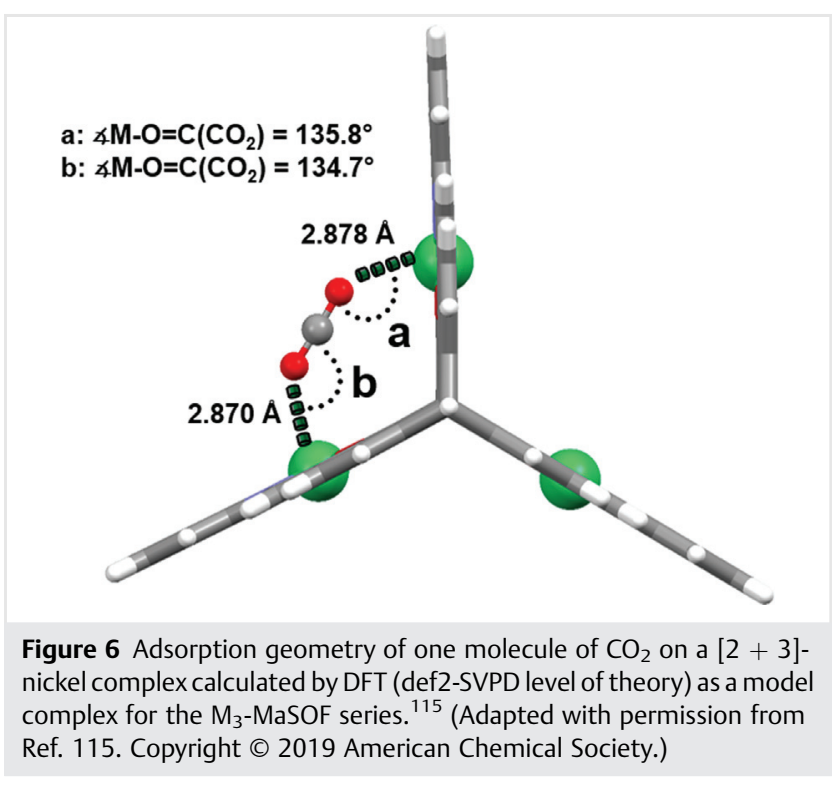


the area of MOFs, ${ }^{117,137}$ the idea was to generate networks that contain trinuclear metal units, where the metals are in close proximity to synergically bind $\mathrm{CO}_{2}$. Indeed, model complexes of these trinuclear units revealed metal-metal distances $\left(d=6.65-6.74 \AA\right.$ ) that should be ideal for $\mathrm{CO}_{2}$ sorption (see above; Scheme 11, Table 2, and Figure 6). ${ }^{115}$ For $\mathrm{Ni}_{3}-\mathrm{MaSOF}_{\mathrm{as}}$, an isosteric heat of adsorption of $\mathrm{Q}_{\mathrm{st}}=35.6 \mathrm{~kJ} / \mathrm{mol}$ (Figure 6 and Figure 7) was measured, which is comparable to the values of some of the bestperforming MOFs such as Ni-MOF-74 $\left(Q_{\text {st }}=37-42\right.$ $\mathrm{kJ} / \mathrm{mol}),{ }^{138}$ HKUST-1 $\left(Q_{\mathrm{st}}=15-35 \mathrm{~kJ} / \mathrm{mol}\right),{ }^{139}$ or MIL-120 $\left(Q_{s t}=38 \mathrm{~kJ} / \mathrm{mol}\right) .{ }^{140}$ The resulting selectivities are $S_{\text {IAST }}$
$=16\left(\mathrm{CO}_{2} / \mathrm{CH}_{4}\right)$ and $S_{\text {IAST }}=89\left(\mathrm{CO}_{2} / \mathrm{N}_{2}\right)$ for $\mathrm{Ni}_{3}-\mathrm{MaSOF}_{\mathrm{as}}$ at 0.1 bar and $273 \mathrm{~K}$ (Table 2 and Figure 7$).{ }^{115}$ To get a deeper insight into the adsorption processes, DFT calculations (def2-SVPD) on the synergic binding of $\mathrm{CO}_{2}$ were performed (Figure 7). A high energy gain for the adsorption of two molecules of $\mathrm{CO}_{2}$ suggests cooperative effects during the adsorption event. This is experimentally supported by a stepwise adsorption of $\mathrm{CO}_{2}$ at $195 \mathrm{~K}$ (Figure 7). Finally, the potential application in gas separation was shown by calculated breakthrough curves which was found to occur after approximately $10 \mathrm{~min}$ for an 80:20 mixture of $\mathrm{N}_{2}$ and $\mathrm{CO}_{2}$ at 1 bar and $1 \mathrm{~L} / \mathrm{min}$ flow
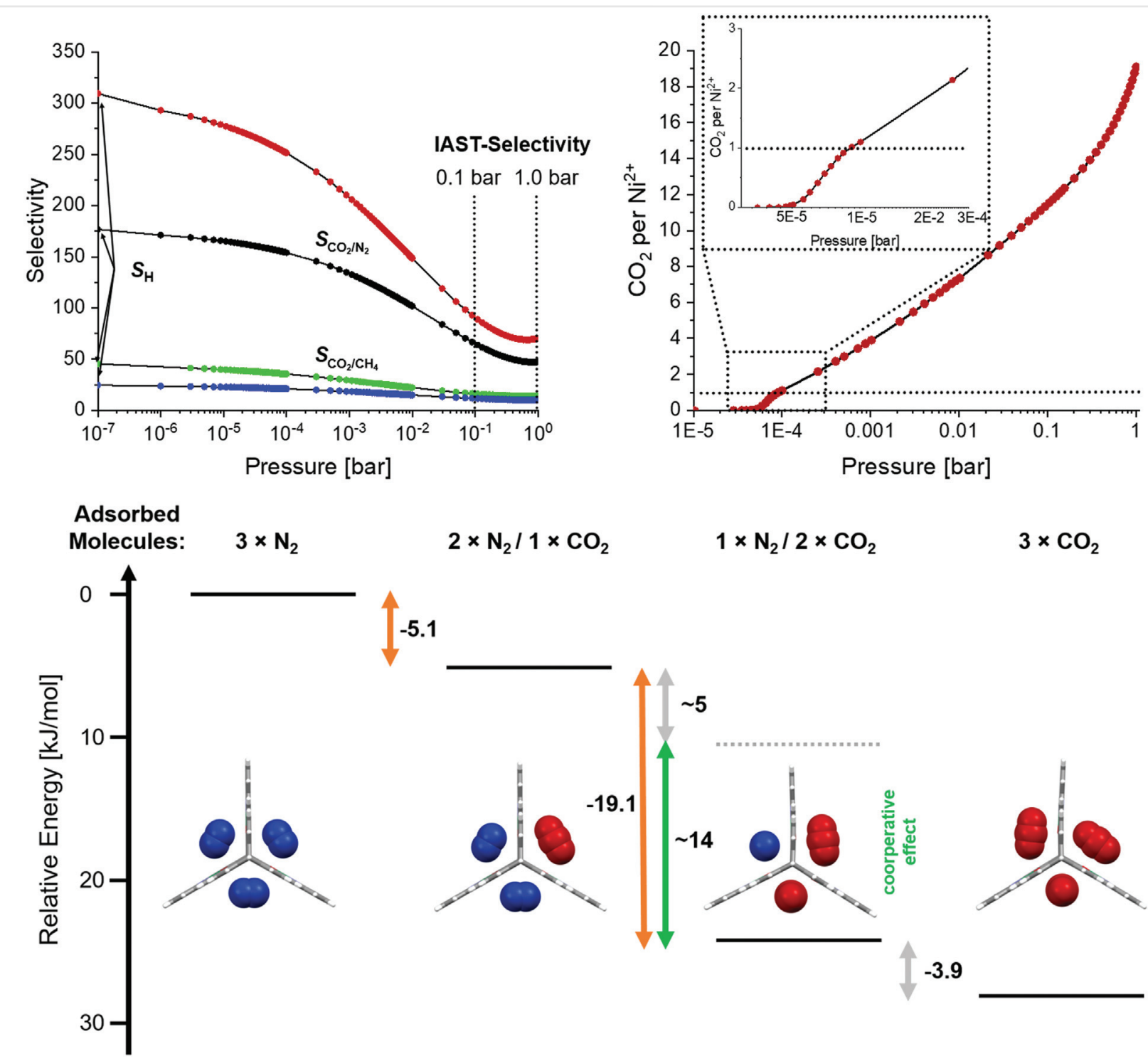

$2 \times \mathrm{N}_{2} / 1 \times \mathrm{CO}_{2}$

$1 \times \mathrm{N}_{2} / 2 \times \mathrm{CO}_{2}$

$3 \times \mathrm{CO}_{2}$
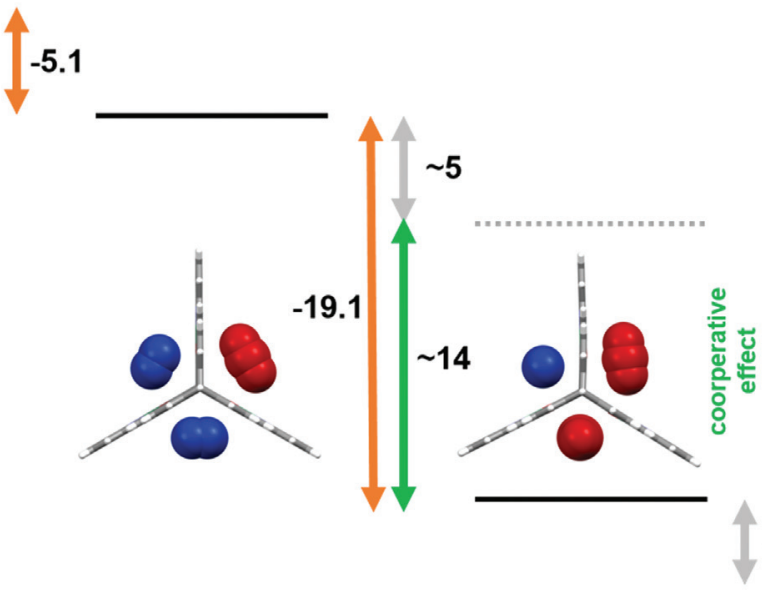

$-3.9$

Figure 7 Top left: IAST selectivities of $\mathrm{Ni}_{3}-\mathrm{MaSOF}_{\text {as }}$ (red and green) and $\mathrm{Ni}_{3}-\mathrm{MaSOF}_{\mathrm{w}}$ (black and blue) at $273 \mathrm{~K}$. Top right: $\mathrm{CO}_{2}$ adsorption isotherm of $\mathrm{Ni}_{3}-\mathrm{MaSOF}_{\text {as }}$ at $195 \mathrm{~K}$. Bottom: relative adsorption energies calculated by DFT (def2-SVPD level of theory) of three molecules of $\mathrm{N}_{2}$ and/or $\mathrm{CO}_{2}$ on a $[2+3]$-nickel model complex. (Adapted with permission from Ref. 115. Copyright @ 2019 American Chemical Society.) 
rate with a hypothetical column of $200 \times 30 \mathrm{~mm}$ and $60 \mathrm{~g}$ of substrate. ${ }^{115}$

\section{Miscellaneous Applications}

In addition to the as-discussed applications, salen- and salphen-containing polymers were used for example as light-emitting materials in solution. ${ }^{103-106,141}$ While some of the polymers were only investigated phenomenologically, ${ }^{103}$ MacLachlan's linear 1D Zn(II)-containing poly(salphenyleneethynylenes) showed a fluorescence enhancement upon addition of Lewis bases such as pyridine, proving a potential application as a fluorescent sensor for such. ${ }^{104 \mathrm{~b}}$ This was further underlined by a series of poly(Pt-salphen)(para-phenyleneethynylenes) providing low-energy emission $\left(\lambda_{\mathrm{Em}} \sim 580-700 \mathrm{~nm}\right)$ with a selective fluorescence quenching in the presence of $\mathrm{Cu}^{2+}$ ions, while other main group and transition metals did not influence the emission properties. $^{105}$

Another example for the use of 1D salen polymers is the metal-free polymer P1, which was used to enantiodiscriminate chiral $\alpha$-hydroxyl carboxylic acids. For instance, for mandelic acid an enantiomeric fluorescence difference ratio (ef) ${ }^{142}$ of up to 8.41 in preference to the $(L)$ enantiomer was found (Figure 8). ${ }^{143}$ When reduced to the corresponding salan polymer, a "turn-off" of the fluorescence was observed, proving again that minor structural

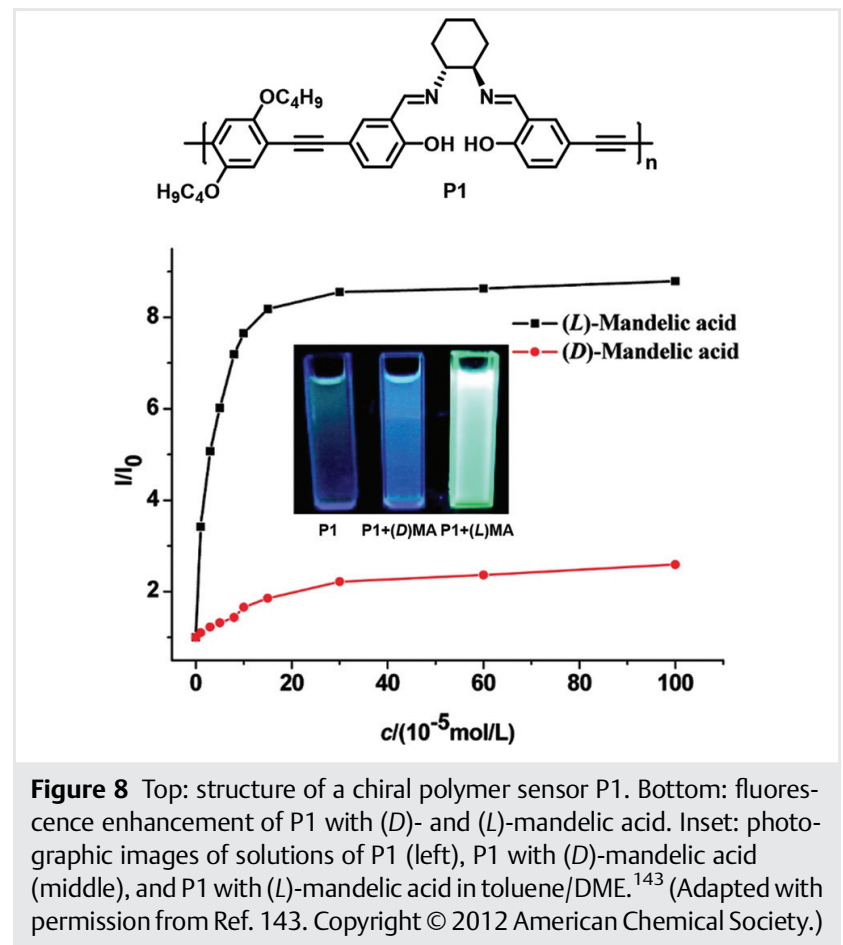

changes in the polymeric backbone can tune the corresponding properties dramatically.

Based on defined pores, the COF-1 $\left(\mathrm{SA}_{\mathrm{BET}}=666 \mathrm{~m}^{2} / \mathrm{g}\right)$ and COF-1-Zn networks $\left(\mathrm{SA}_{\mathrm{BET}}=460 \mathrm{~m}^{2} / \mathrm{g}\right.$; see Scheme 11) were used as the stationary phase for HPLC to separate mixtures of ethylbenzene and xylene isomers (Figure 9). ${ }^{125}$ With metal-free COF-1, baseline separation was observed with separation factors $\alpha$ of up to 2.0, resolution factors $R$ of up to 5.2 as well as high effective theoretical plate numbers of up to 10980 . These are in the range or even higher than those of, for example, stationary-phase bases on MOFs. ${ }^{144}$

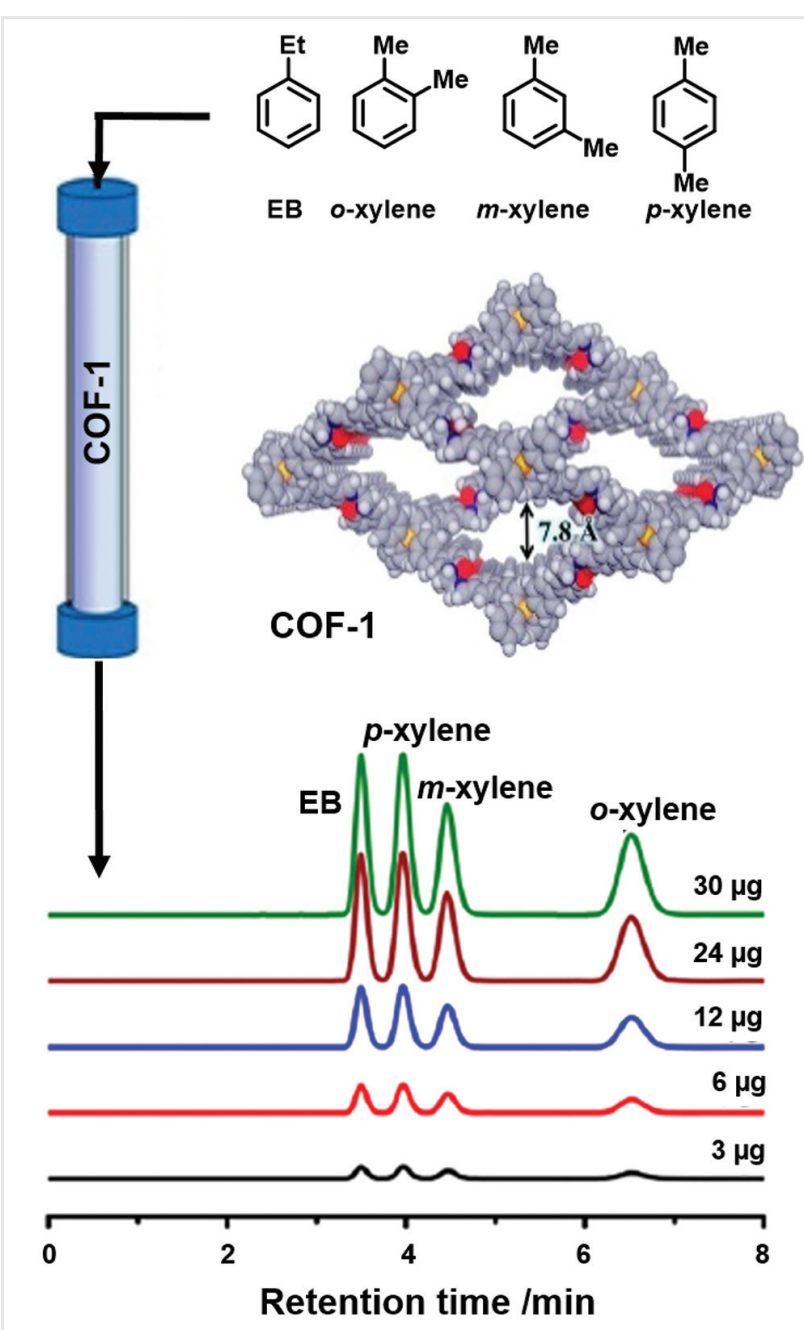

Figure 9 Representative chromatogram of a column packed with COF1 (Scheme 15) used for the separation of ethylbenzene (EB) and xylene isomers upon different sample loading (depicted on the right). ${ }^{144}$ (Adapted with permission from Ref. 144. Copyright @ 2019 American Chemical Society.) 


\section{Conclusions and Outlook}

To summarize, salen and salphen units and their corresponding metal complexes have been introduced into $1 \mathrm{D}, 2 \mathrm{D}$, and $3 \mathrm{D}$ polymers and depending on the dimensionality and properties used for several applications. For instance, most 1D salphen polymers are conjugated compounds and thus it is not surprising that these have been investigated as conductive films, for example, to tune the redox properties of electrodes or the resistivity of multiwalled carbon nanotubes. Furthermore, some of the compounds show fluorescence and in combination with various Lewis acidic metal centers have been used for sensing by fluorescence quenching. If chiral salens instead of salphens are embedded into the polymer backbone, the sensing applications are broadened to chiral discrimination. It is worth mentioning that some of the first chiral helical ladder polymers synthesized by Katz and coworkers are based on the formation of metal salphens. There were three main synthetic approaches towards 1D polysalphens established: electropolymerization, condensation of aldehyde and amine moieties to imines, forming the salphen pockets, or cross-coupling reactions. The two latter have been used to make 2D salphen polymers as well. However, electropolymerization has not been used therefor. The vast majority of $2 \mathrm{D}$ as well as 3D salphen polymers are porous and therefore it is not surprising that in combination with the embedded metal centers, these have been used for catalytic applications as well as gas sorption and separation of smaller molecules. In both fields there are some materials that are comparable or even superior to similar compounds. For instance, some of the 2D chiral metal salen COFs are excellent catalysts for a number of asymmetric transformations, giving products in high yields and high ee values, thus perfectly combining heterogeneous reactivity with high surface areas. Due to the fact that almost all of the described 2D-salphene polymers are crystalline and being reported that the sheets are packed in an eclipsed fashion, the vast majority of metal salphen centers are not accessible for catalytic reactions or interactions with gases. Therefore, it is just logical that salphen COFs and polymers will be taken to the third dimension. Till date only a handful of 3D salphen polymers are known, but certainly they will be exploited in the future to enhance catalytic activities and gas sorption properties even more. The large plethora of metals that can be complexed by salen and salphen units as well as organic building blocks to construct polymers allows an infinite access of new materials with exciting properties.

\section{References}

(1) Combes, A. C. R. Acad. Fr. 1889, 108, 1252.

(2) (a) Takeuchi, T.; Böttcher, A.; Quezada, C. M.; Meade, T.J.; Gray, H. B. Bioorg. Med. Chem. 1999, 7, 815. (b) Kwiatkowski, E.;
Kwiatkowski, M. Inorg. Chim. Acta 1980, 42, 197. (c) Dedieu, A.; Rohmer, M. M.; Veillard, A. J. Am. Chem. Soc. 1976, 98, 5789. (d) Böttcher, A.; Takeuchi,T.; Hardcastle, K. I.; Meade, T.J.; Gray, H. B.; Cwikel, D.; Kapon, M.; Dori, Z. Inorg. Chem. 1997, 36, 2498.

(3) (a) Matsumoto, K.; Oguma, T.; Katsuki, T. Angew. Chem. Int. Ed. 2009, 48, 7432. (b) Atwood, D. A. Coord. Chem. Rev. 1997, 165, 267. (c) Adão, P.; Costa Pessoa, J.; Henriques, R. T.; Kuznetsov, M. L.; Avecilla, F.; Maurya, M. R.; Kumar, U.; Correia, I. Inorg. Chem. 2009, 48, 3542.

(4) (a) Whitelaw, E. L.; Loraine, G.; Mahon, M. F.; Jones, M. D. Dalton Trans. 2011, 40, 11469. (b) Whitelaw, E. L.; Davidson, M. G.; Jones, M. D. Chem. Commun. 2011, 47, 10004. (c) Matsumoto, K.; Saito, B.; Katsuki, T. Chem. Commun. 2007, 35, 3619. (d) Whitelaw, E. L.; Jones, M. D.; Mahon, M. F. Inorg. Chem. 2010, 49, 7176.

(5) (a) Li, X-Y.; Chen, L.; Gao, L.; Zhang, Y.; Akogun, S. F.; Dong, W-K. RSC Adv. 2017, 7, 35905. (b) Dong, Y-J.; Dong, X-Y.; Dong, W-K.; Zhang, Y.; Zhang, L-S. Polyhedron 2017, 123, 305. (c) Dong, WK.; Li, X-L.; Wang, L.; Zhang, Y.; Ding, Y-J. Sens. Actuators, $B$ 2016, 229, 370. (d) Akine, S.; Taniguchi, T.; Nabeshima, T. Inorg. Chem. 2004, 43, 6142.

(6) (a) Akine, S.; Nabeshima, T. Inorg. Chem. 2005, 44, 1205. (b) Yilmaz, I.; Temel, H.; Alp, H. Polyhedron 2008, 27, 125. (c) Sowden, R. J.; Trotter, K. D.; Dunbar, L.; Craig, G.; Erdemli, O.; Spickett, C. M.; Reglinski, J. Biometals 2013, 26, 85. (d) Patchett, R.; Magpantay, I.; Saudan, L.; Schotes, C.; Mezzetti, A.; Santoro, F. Angew. Chem. Int. Ed. 2013, 52, 10352. (e) Fernandes, R. R.; Lasri, J.; Kirillov, A. M.; d. Silva, M. F. C. G.; d. Silva, J. A. L.; d. Silva, J. J. R. F.; Pombeiro, A. J. L. Eur. J. Inorg. Chem. 2011, 2011, 3781. (f) Cox, K.; Kariuki, B. M.; Smyth, A.; Newman, P. D. Dalton Trans. 2016, 45, 8485.

(7) (a) Katsuki, T. Coord. Chem. Rev. 1995, 140, 189. (b) Whiteoak, C. J.; Salassa, G.; Kleij, A. W. Chem. Soc. Rev. 2012, 41, 622. (c) Canali, L.; Sherrington, D. C. Chem. Soc. Rev. 1999, 28, 85. (d) McGarrigle, E. M.; Gilheany, D. G. Chem. Rev. 2005, 105, 1563. (e) Cozzi, P. G. Chem. Soc. Rev. 2004, 33, 410.

(8) (a) Sasaki, H.; Irie, R.; Hamada, T.; Suzuki, K.; Katsuki, T. Tetrahedron 1994, 50, 11827. (b) Jacobsen, E. N.; Zhang, W.; Muci, A. R.; Ecker, J. R.; Deng, L. J. Am. Chem. Soc. 1991, 113, 7063. (c) Irie, R.; Noda, K.; Ito, Y.; Matsumoto, N.; Katsuki, T. Tetrahedron: Asymmetry 1991, 2, 481. (d) Irie, R.; Noda, K.; Ito, Y.; Matsumoto, N.; Katsuki, T. Tetrahedron Lett. 1990, 31, 7345.

(9) (a) Hamachi, K.; Irie, R.; Katsuki, T. Tetrahedron Lett. 1996, 37, 4979. (b) Nishinaga, A.; Yamato, H.; Abe, T.; Maruyama, K.; Matsuura, T. Tetrahedron Lett. 1988, 29, 6309.

(10) Fukuda, T.; Katsuki, T. Synlett 1995, 1995, 825.

(11) (a) Palucki, M.; Hanson, P.; Jacobsen, E. N. Tetrahedron Lett. 1992, 33, 7111. (b) Reddy, D. R.; Thornton, E. R. J. Chem. Soc., Chem. Commun. 1992, 172. (c) Adam, W.; Fell, R. T.; Stegmann, V. R.; Saha-Möller, C. R. J. Am. Chem. Soc. 1998, 120, 708. (d) Caori, S.; Kiyohiko, N.; Masaaki, K.; Junnosuke, F. Bull. Chem. Soc. Jpn. 1991, 64, 1318.

(12) O'Connor, K. J.; Wey, S-J.; Burrows, C. J. Tetrahedron Lett. 1992, 33, 1001.

(13) (a) Jacobsen, E. N.; Kakiuchi, F.; Konsler, R. G.; Larrow, J. F.; Tokunaga, M. Tetrahedron Lett. 1997, 38, 773. (b) Wu, M. H.; Jacobsen, E. N. Tetrahedron Lett. 1997, 38, 1693.

(14) Schaus, S. E.; Brånalt, J.; Jacobsen, E. N.J. Org. Chem. 1998, 63, 403.

(15) North, M.; Orizu, C.; Tararov, V. I.; Ikonnikov, N. S.; Belokon, Y. N.; Hibbs, D. E.; Hursthouse, M. B.; Abdul Malik, K. M. Chem. Commun. 1998, 387.

(16) Balasanthiran, V.; Chisholm, M. H.; Durr, C. B. Dalton Trans. 2015, 44, 8205. 
(17) Reglinski, J.; Kennedy, A. R.; Steel, G. New J. Chem. 2015, 39, 2437.

(18) Cui, Y.; Jiang, J.; Mao, X.; Wu, J. Inorg. Chem. 2019, 58, 218.

(19) Corazza, F.; Floriani, C.; Chiesi-Villa, A.; Guastini, C.; Ciurli, S. J. Chem. Soc., Dalton Trans. 1988, 2341.

(20) Spassky, N.; Wisniewski, M.; Pluta, C.; Le Borgne, A. Macromol. Chem. Phys. 1996, 197, 2627.

(21) Wagler, J.; Böhme, U.; Roewer, G. Angew. Chem. Int. Ed. 2002, 41, 1732.

(22) Agustin, D.; Rima, G.; Gornitzka, H.; Barrau, .J. Organometallics 2000, 19, 4276.

(23) Sánchez, M.; Harvey, M. J.; Nordstrom, F.; Parkin, S.; Atwood, D. A. Inorg. Chem. 2002, 41, 5397.

(24) Meermann, C.; Sirsch, P.; Törnroos, K. W.; Anwander, R. Dalton Trans. 2006, 1041.

(25) Floriani, C.; Solari, E.; Corazza, F.; Chiesi-Villa, A.; Guastini, C. Angew. Chem. 1989, 101, 91.

(26) Seangprasertkij, R.; Riechel, T. L. Inorg. Chem. 1986, 25, 3121.

(27) Coggon, P.; McPhail, A. T.; Mabbs, F. E.; Richards, A.; Thornley, A. S. J. Chem. Soc. A 1970, 3296.

(28) Wiznycia, A. V.; Desper, J.; Levy, C. J. Chem. Commun. 2005, 4693.

(29) Darensbourg, D. J.; Ortiz, C. G.; Billodeaux, D. R. Inorg. Chim. Acta 2004, 357, 2143.

(30) Pizzolato, E.; Natali, M.; Posocco, B.; Montellano Lopez, A.; Bazzan, I.; Di Valentin, M.; Galloni, P.; Conte, V.; Bonchio, M.; Scandola, F.; Sartorel, A. Chem. Commun. 2013, 49, 9941.

(31) Amirnasr, M.; Schenk, K. J.; Gorji, A.; Vafazadeh, R. Polyhedron 2001, 20, 695.

(32) Chong, J. H.; Ardakani, S. J.; Smith, K. J.; MacLachlan, M. J. Chem. Eur. J. 2009, 15, 11824.

(33) Klement, R.; Stock, F.; Elias, H.; Paulus, H.; Pelikán, P.; Valko, M.; Mazúr, M. Polyhedron 1999, 18, 3617.

(34) Anselmo, D.; Salassa, G.; Escudero-Adán, E. C.; Martin, E.; Kleij, A. W. Dalton Trans. 2013, 42, 7962.

(35) Shen, Y-Z.; Pan, Y.; Wang, L-Y.; Dong, G.; Jin, X-P.; Huang, X-Y.; Hu, H. J. Organomet. Chem. 1999, 590, 242.

(36) Agustin, D.; Rima, G.; Gornitzka, H.; Barrau, J. J. Organomet. Chem. 1999, 592, 1.

(37) Costes, J-P.; Dupuis, A.; Laurent, J-P. Inorg. Chim. Acta 1998, 268, 125.

(38) Zhu, H.; Wang, M.; Ma, C.; Li, B.; Chen, C.; Sun, L. J. Organomet. Chem. 2005, 690, 3929.

(39) Floriani, C.; Solari, E.; Franceschi, F.; Scopelliti, R.; Belanzoni, P.; Rosi, M. Chem. Eur. J. 2001, 7, 3052.

(40) Luts, T.; Frank, R.; Suprun, W.; Fritzsche, S.; Hey-Hawkins, E.; Papp, H. J. Mol. Catal. A: Chem. 2007, 273, 250.

(41) Jurisson, S.; Lindoy, L. F.; Dancey, K. P.; McPartlin, M.; Tasker, P. A.; Uppal, D. K.; Deutsch, E. Inorg. Chem. 1984, 23, 227.

(42) Chichak, K.; Jacquemard, U.; Branda, N. R. Eur. J. Inorg. Chem. 2002, 357.

(43) Rogers, C. A.; West, B. O. J. Organomet. Chem. 1974, 70, 445.

(44) Yoon, I.; Narita, M.; Shimizu, T.; Asakawa, M. J. Am. Chem. Soc. 2004, 126, 16740.

(45) Barwiolek, M.; Sawicka, J.; Babinska, M.; Wojtczak, A.; Surdykowski, A.; Szczesny, R.; Szlyk, E. Polyhedron 2017, 135, 153.

(46) Tajmir-Riahi, H. A. Polyhedron 1983, 2, 723.

(47) Sharma, P.; Rosas, N.; Ramashankar, A. Main Group Met Chem 1995, 18, 621.

(48) Srivastava, T. N.; Chauhan, A. K. S.; Mehrotra, G. K. Synth. React. Inorg. Met.-Org. Chem. 1982, 12, 705.

(49) Klamm, B. E.; Windorff, C. J.; Marsh, M. L.; Meeker, D. S.; Albrecht-Schmitt, T. E. Chem. Commun. 2018, 54, 8634.
(50) Costes, J-P.; Laussac, J-P.; Nicodème, F. J. Chem. Soc., Dalton Trans. 2002, 2731.

(51) Taha, Z. A.; Ajlouni, A. M.; Al Momani, W.; Al-Ghzawi, A. A. Spectrochim. Acta, Part A 2011, 81, 570.

(52) Tsuchimoto, M.; Ookusa, M.; Itoh, S.; Watanabe, M.; Nakajima, K. Polyhedron 2018, 148, 118.

(53) Berardozzi, R.; Pescitelli, G.; Di Pietro, S.; Resta, C.; Ballistreri, F. P.; Pappalardo, A.; Tomaselli, G. A.; Di Bari, L. Chirality 2015, 27, 857.

(54) Tyagi, S. B.; Singh, B.; Kapoor, R. N. Transition Met. Chem. 1987, $12,405$.

(55) Santini-Scampucci, C.; Wilkinson, G. J. Chem. Soc., Dalton Trans. 1976, 807.

(56) Yeung, K. T.; To, W. P.; Sun, C.; Cheng, G.; Ma, C.; Tong, G. S. M.; Yang, C.; Che, C. M. Angew. Chem. Int. Ed. 2017, 56, 133.

(57) Ison, E. A.; Cessarich, J. E.; Du, G.; Fanwick, P. E.; Abu-Omar, M. M. Inorg. Chem. 2006, 45, 2385.

(58) Che, C. M.; Cheng, W. K.; Mak, T. C. W. Inorg. Chem. 1986, 25, 703.

(59) Mercati, G.; Morazzoni, F. J. Chem. Soc., Dalton Trans. 1979, 569.

(60) Guo, Z.; Yiu, S-M.; Chan, M. C. W. Chem. Eur. J. 2013, 19, 8937.

(61) Barnholtz, S. L.; Lydon, J. D.; Huang, G.; Venkatesh, M.; Barnes, C. L.; Ketring, A. R.; Jurisson, S. S. Inorg. Chem. 2001, 40, 972.

(62) Pellerito, L.; Cefalù, R.; Ruisi, G. J. Organomet. Chem. 1972, 44, 243.

(63) Balasanthiran, V.; Chisholm, M. H.; Durr, C. B.; Gallucci, J. C. Dalton Trans. 2013, 42, 11234.

(64) Agarwal, D. D.; Srivastava, S.; Chadha, P. Polyhedron 1990, 9, 1401.

(65) Brancatelli, G.; Pappalardo, A.; Trusso Sfrazzetto, G.; Notti, A.; Geremia, S. Inorg. Chim. Acta 2013, 396, 25

(66) Copping, R.; Mougel, V.; Den Auwer, C.; Berthon, C.; Moisy, P.; Mazzanti, M. Dalton Trans. 2012, 41, 10900.

(67) Zhang, H-C.; Huang, W-S.; Pu, L. J. Org. Chem. 2001, 66, 481.

(68) (a) Dai, Y.; Katz, T. J.; Nichols, D. A. Angew. Chem. Int. Ed. 1996, 35, 2109. (b) Dai, Y.; Katz, T. J. J. Org. Chem. 1997, 62, 1274.

(69) Xu, Z-X.; Huang, Z-T.; Chen, C-F. Tetrahedron Lett. 2009, 50, 5430.

(70) Escárcega-Bobadilla, M. V.; Salassa, G.; Martínez Belmonte, M.; Escudero-Adán, E. C.; Kleij, A. W. Chem. Eur. J. 2012, 18, 6805.

(71) (a) Zintl, M.; Molnar, F.; Urban, T.; Bernhart, V.; PreishuberPflügl, P.; Rieger, B. Angew. Chem. Int. Ed. 2008, 47, 3458. (b) Vagin, S. I.; Reichardt, R.; Klaus, S.; Rieger, B. J. Am. Chem. Soc. 2010, 132, 14367. (c) Vagin, S.; Winnacker, M.; Kronast, A.; Altenbuchner, P. T.; Deglmann, P.; Sinkel, C.; Loos, R.; Rieger, B. ChemCatChem 2015, 7, 3963. (d) Reichardt, R.; Vagin, S.; Reithmeier, R.; Ott, A. K.; Rieger, B. Macromolecules 2010, 43, 9311. (e) Mandal, M.; Chakraborty, D. J Polym Sci A Polym Chem 2016, 54, 809.

(72) (a) Castro-Gómez, F.; Salassa, G.; Kleij, A. W.; Bo, C. Chem. Eur.J. 2013, 19, 6289. (b) Decortes, A.; Kleij, A. W. ChemCatChem 2011, 3, 831. (c) Castro-Osma, J. A.; North, M.; Wu, X. Chem. Eur. J. 2016, 22, 2100. (d) Martín, R.; Kleij, A. W. ChemSusChem 2011, 4, 1259 .

(73) (a) Taherimehr, M.; Decortes, A.; Al-Amsyar, S. M.; Lueangchaichaweng, W.; Whiteoak, C. J.; Escudero-Adan, E. C.; Kleij, A. W.; Pescarmona, P. P. Catal. Sci. Technol. 2012, 2, 2231. (b) Escudero-Adán, E. C.; Benet-Buchholz, J.; Kleij, A. W. Chem. Eur. J. 2009, 15, 4233. (c) Kleij, A. W.; Lutz, M.; Spek, A. L.; van Leeuwen, P. W. N. M.; Reek, J. N. H. Chem. Commun. 2005, 3661. (d) Dalla Cort, A.; Mandolini, L.; Pasquini, C.; Rissanen, K.; Russo, L.; Schiaffino, L. New J. Chem. 2007, 31, 1633. 
(74) (a) Theil, H.; von Richthofen, C-GF.; Stammler, A.; Bögge, H.; Glaser, T. Inorg. Chim. Acta 2008, 361, 916. (b) Sakata, Y.; Murata, C.; Akine, S. Nat. Commun. 2017, 8, 16005. (c) Houjou, H.; Ito, M.; Araki, K. Inorg. Chem. 2009, 48, 10703. (d) Glaser, T.; Heidemeier, M.; Krickemeyer, E.; Bögge, H.; Stammler, A.; Fröhlich, R.; Bill, E.; Schnack, J. Inorg. Chem. 2009, 48, 607. (e) Glaser, T.; Heidemeier, M.; Fröhlich, R.; Hildebrandt, P.; Bothe, E.; Bill, E. Inorg. Chem. 2005, 44, 5467. (f) Bazarnik, M.; Bugenhagen, B.; Elsebach, M.; Sierda, E.; Frank, A.; Prosenc, M. H.; Wiesendanger, R. Nano Lett. 2016, 16, 577.

(75) (a) Borisova, N. E.; Reshetova, M. D.; Ustynyuk, Y. A. Chem. Rev. 2007, 107, 46. (b) Akine, S.; Taniguchi, T.; Nabeshima, T. Tetrahedron Lett. 2001, 42, 8861. (c) Hui, J. K. H.; MacLachlan, M. J. Chem. Commun. 2006, 2480. (d) Gallant, A. J.; Chong, J. H.; MacLachlan, M. J. Inorg. Chem. 2006, 45, 5248. (e) Frischmann, P. D.; Facey, G. A.; Ghi, P. Y.; Gallant, A. J.; Bryce, D. L.; Lelj, F.; MacLachlan, M. J. J. Am. Chem. Soc. 2010, 132, 3893. (f) Nabeshima, T.; Miyazaki, H.; Iwasaki, A.; Akine, S.; Saiki, T.; Ikeda, C. Tetrahedron 2007, 63, 3328. (g) Frischmann, P. D.; Mehr, S. H. M.; Patrick, B. O.; Lelj, F.; MacLachlan, M. J. Inorg. Chem. 2012, 51, 3443.

(76) (a) Sakata, Y.; Chiba, S.; Miyashita, M.; Nabeshima, T.; Akine, S. Chem. Eur. J. 2019, 25, 2962. (b) Ng, C. K.; Toh, R. W.; Lin, T. T.; Luo, H-K.; Hor, T. S. A.; Wu, J. Chem. Sci. 2019, 10, 1549. (c) Lai, J.; Ke, X-S.; Tang, J.; Zhang, J-L. Chin. Chem. Lett. 2015, 26, 937. (d) Akine, S.; Piao, S.; Miyashita, M.; Nabeshima, T. Tetrahedron Lett. 2013, 54, 6541. (e) Akine, S.; Miyashita, M.; Piao, S.; Nabeshima, T. Inorg. Chem. Front. 2014, 1, 53. (f) Akine, S.; Miyashita, M.; Nabeshima, T. Chem. Eur. J. 2019, 25, 1432. (g) Akine, S.; Miyashita, M.; Nabeshima, T. J. Am. Chem. Soc. 2017, 139, 4631.

(77) (a) Mastalerz, M. Acc. Chem. Res. 2018, 51, 2411. (b) Zhang, G.; Mastalerz, M. Chem. Soc. Rev. 2014, 43, 1934. (c) Mastalerz, M. Angew. Chem. Int. Ed. 2010, 49, 5042. (d) Beuerle, F.; Gole, B. Angew. Chem. Int. Ed. 2018, 57, 4850. (e) Santolini, V.; Miklitz, M.; Berardo, E.; Jelfs, K. E. Nanoscale 2017, 9, 5280. (f) Acharyya, K.; Mukherjee, P. S. Angew. Chem. Int. Ed. 2019, 58, 8640. (g) Rue, N. M.; Sun, J.; Warmuth, R. Isr. J. Chem. 2011, 51, 743.

(78) (a) Kuil, M.; Puijk, I. M.; Kleij, A. W.; Tooke, D. M.; Spek, A. L.; Reek, J. N. H. Chem. Asian J. 2009, 4, 50. (b) Kleij, A. W.; Kuil, M.; Tooke, D. M.; Lutz, M.; Spek, A. L.; Reek, J. N. H. Chem. Eur. J. 2005, 11, 4743.

(79) (a) Xuan, W.; Zhang, M.; Liu, Y.; Chen, Z.; Cui, Y.J. Am. Chem. Soc. 2012, 134, 6904. (b) Tan, C.; Jiao, J.; Li, Z.; Liu, Y.; Han, X.; Cui, Y. Angew. Chem. Int. Ed. 2018, 57, 2085. (c) Jiao, J.; Tan, C.; Li, Z.; Liu, Y.; Han, X.; Cui, Y. J. Am. Chem. Soc. 2018, 140, 2251. (d) Dong, J.; Zhou, Y.; Zhang, F.; Cui, Y. Chem. Eur. J. 2014, 20, 6455.

(80) Dong, J.; Tan, C.; Zhang, K.; Liu, Y.; Low, P. J.; Jiang, J.; Cui, Y. J. Am. Chem. Soc. 2017, 139, 1554.

(81) (a) Kitaura, R.; Onoyama, G.; Sakamoto, H.; Matsuda, R.; Noro, S-i.; Kitagawa, S. Angew. Chem. Int. Ed. 2004, 43, 2684. (b) Oh, M.; Mirkin, C. A. Nature 2005, 438, 651. (c) Cho, S-H.; Ma, B.; Nguyen, S. T.; Hupp, J. T.; Albrecht-Schmitt, T. E. Chem. Commun. 2006, 24, 2563. (d) Oh, M.; Mirkin, C. A. Angew. Chem. Int. Ed. 2006, 45, 5492. (e) Heo, J.; Jeon, Y-M.; Mirkin, C. A. J. Am. Chem. Soc. 2007, 129, 7712. (f) Jeon, Y-M.; Heo, J.; Mirkin, C. A.J. Am. Chem. Soc. 2007, 129, 7480. (g) Jeon, Y-M.; Armatas, G. S.; Heo, J.; Kanatzidis, M. G.; Mirkin, C. A. Adv. Mater. 2008, 20 , 2105. (h) Jung, S.; Oh, M. Angew. Chem. Int. Ed. 2008, 47, 2049. (i) Bhunia, A.; Roesky, P. W.; Lan, Y.; Kostakis, G. E.; Powell, A. K. Inorg. Chem. 2009, 48, 10483. (j) Jung, S.; Cho, W.; Lee, H. J.; Oh, M. Angew. Chem. Int. Ed. 2009, 48, 1459. (k) Li, G.; Zhu, C.; Xi, X.;
Cui, Y. Chem. Commun. 2009, 2118. (1) Yuan, G.; Zhu, C.; Xuan, W.; Cui, Y. Chem. Eur. J. 2009, 15, 6428. (m) Song, F.; Wang, C.; Falkowski, J. M.; Ma, L.; Lin, W. J. Am. Chem. Soc. 2010, 132, 15390. (n) Bhunia, A.; Lan, Y.; Mereacre, V.; Gamer, M. T.; Powell, A. K.; Roesky, P. W. Inorg. Chem. 2011, 50, 12697. (o) Falkowski, J. M.; Wang, C.; Liu, S.; Lin, W. Angew. Chem. Int. Ed. 2011, 50, 8674. (p) Huang, Y.; Liu, T.; Lin, J.; Lü, J.; Lin, Z.; Cao, R. Inorg. Chem. 2011, 50, 2191. (q) Roesky, P. W.; Bhunia, A.; Lan, Y.; Powell, A. K.; Kureti, S. Chem. Commun. 2011, 47, 2035. (r) Shultz, A. M.; Sarjeant, A. A.; Farha, O. K.; Hupp, J. T.; Nguyen, S. T. J. Am. Chem. Soc. 2011, 133, 13252. (s) Song, F.; Wang, C.; Lin, W. Chem. Commun. 2011, 47, 8256. (t) Wang, C.; Zheng, M.; Lin, W. J. Phys. Chem. Lett. 2011, 2, 1701. (u) Xiang, S-C.; Zhang, Z.; Zhao, C-G.; Hong, K.; Zhao, X.; Ding, D-R.; Xie, M-H.; Wu, C-D.; Das, M. C.; Gill, R.; Thomas, K. M.; Chen, B. Nat. Commun. 2011, 2, 204. (v) Falkowski, J. M.; Liu, S.; Wang, C.; Lin, W. Chem. Commun. 2012, 48, 6508. (w) Zhu, C.; Yuan, G.; Chen, X.; Yang, Z.; Cui, Y. J. Am. Chem. Soc. 2012, 134, 8058. (x) Ren, Y.; Shi, Y.; Chen, J.; Yang, S.; Qi, C.; Jiang, H. RSC Adv. 2013, 3, 2167. (y) Li, J.; Yang, J.; Liu, Y. Y.; Ma, J. F. Chem. Eur. J. 2015, 21, 4413. (z) Xi, W.; Liu, Y.; Xia, Q.; Li, Z.; Cui, Y. Chem. Eur. J. 2015, 21, 12581. (aa) Bhunia, A.; Dey, S.; Moreno, J. M.; Diaz, U.; Concepcion, P.; Van Hecke, K.; Janiak, C.; Van Der Voort, P. Chem. Commun. 2016, 52, 1401. (ab) Xia, Q.; Liu, Y.; Li, Z.; Gong, W.; Cui, Y. Chem. Commun. 2016, 52, 13167. (ac) Zhu, C.; Xia, Q.; Chen, X.; Liu, Y.; Du, X.; Cui, Y. ACS Catal. 2016, 6, 7590.

(82) (a) McKeown, N. B. J. Mater. Chem. 2000, 10, 1979. (b) Manners, I. Science 2001, 294, 1664. (c) Baleizão, C.; Garcia, H. Chem. Rev. 2006, 106, 3987.

(83) (a) Li, H.; Hill, M. R.; Huang, R.; Doblin, C.; Lim, S.; Hill, A. J.; Babarao, R.; Falcaro, P. Chem. Commun. 2016, 52, 5973. (b) Yang, S.; Peng, L.; Sun, D. T.; Asgari, M.; Oveisi, E.; Trukhina, O.; Bulut, S.; Jamali, A.; Queen, W. L. Chem. Sci. 2019, 10, 4542.

(84) (a) Wezenberg, S. J.; Kleij, A. W. Angew. Chem. Int. Ed. 2008, 47, 2354. (b) Yuan, G.; Jiang, H.; Zhang, L.; Liu, Y.; Cui, Y. Coord. Chem. Rev. 2019, 378, 483. (c) Crane, A. K.; MacLachlan, M. J. Eur. J. Inorg. Chem. 2012, 2012, 17.

(85) Waltman, R. J.; Bargon, J. Can. J. Chem. 1986, 64, 76.

(86) Boffa, L. S. Applied Polymer Science: 21 st Century. Craver, C. D.; Carraher, C. E., eds. Pergamon: Oxford; 2000, 1021-1042.

(87) Odian, G. Princiles of Polymerization. 4th edn. John Wiley \& Sons, Inc.: Hoboken, NJ, 2004.

(88) Marvel, C. S.; Tarköy, N. J. Am. Chem. Soc. 1957, 79, 6000.

(89) Marvel, C. S.; Tarköy, N. J. Am. Chem. Soc. 1958, 80, 832.

(90) (a) Manecke, V. G.; Wille, W. E. Makromol. Chem. 1970, 133, 61. (b) Manecke, G.; Wille, W. E.; Kossmehl, G. Makromol. Chem. 1972, 160, 111.

(91) Goldsby, K. A. J. Coord. Chem. 1988, 19, 83.

(92) (a) Hoferkamp, L. A.; Goldsby, K. A. Chem. Mater. 1989, 1, 348. (b) Goldsby, K. A.; Blaho, J. K.; Hoferkamp, L. A. Polyhedron 1989, 8, 113.

(93) (a) Dahm, C. E.; Peters, D. G. Anal. Chem. 1994, 66, 3117. (b) Vilas-Boas, M.; Freire, C.; de Castro, B.; Christensen, P. A.; Hillman, A. R. Inorg. Chem. 1997, 36, 4919.

(94) (a) Reddinger, J. L.; Reynolds, J. R. Macromolecules 1997, 30, 673. (b) Reddinger, J. L.; Reynolds, J. R. Chem. Mater. 1998, 10, 3. (c) Kingsborough, R. P.; Swager, T. M. Adv. Mater. 1998, 10, 1100.

(95) Kingsborough, R. P.; Swager, T. M.J. Am. Chem. Soc. 1999, 121, 8825.

(96) Tchepournaya, I.; Vasilieva, S.; Logvinov, S.; Timonov, A.; Amadelli, R.; Bartak, D. Langmuir 2003, 19, 9005.

(97) Holliday, B. J.; Stanford, T. B.; Swager, T. M. Chem. Mater. 2006, $18,5649$. 
(98) (a) Chen, C.; Zhu, Z.; Li, X.; Li, J. J. Appl. Polym. Sci. 2017, 134, 44464. (b) Tedim, J.; Gonçalves, F.; Pereira, M. F. R.; Figueiredo, J. L.; Moura, C.; Freire, C.; Hillman, A. R. Electrochim. Acta 2008, 53, 6722. (c) Gao, F.; Li, J.; Kang, F.; Zhang, Y.; Wang, X.; Ye, F.; Yang, J. J. Phys. Chem. C 2011, 115, 11822.

(99) (a) Zhang, Y.; Li, J.; Gao, F.; Kang, F.; Wang, X.; Ye, F.; Yang, J. Electrochim. Acta 2012, 76, 1. (b) Chen, C.; Li, X.; Deng, F.; Li, J. RSC Adv. 2016, 6, 79894.

(100) (a) Wittung, P.; Nielsen, P. E.; Buchardt, O.; Egholm, M.; Nordén, B. Nature 1994, 368, 561. (b) Leslie, A. G. W.; Arnott, S.; Chandrasekaran, R.; Ratliff, R. L. J. Mol. Biol. 1980, 143, 49.

(101) (a) Yoshio, F.; Takeshi, M.; Takeshi, T.; Nobuaki, M.; Toshikazu, T. Chem. Lett. 2001, 30, 1020. (b) Maeda, T.; Furusho, Y.; Takata, T. Chirality 2002, 14, 587. (c) Maeda, T.; Takeuchi, T.; Furusho, Y.; Takata, T. J. Polym. Sci., Part A: Polym. Chem. 2004, 42, 4693.

(102) (a) Houjou, H.; Shimizu, Y.; Koshizaki, N.; Kanesato, M. Adv. Mater. 2003, 15, 1458. (b) Houjou, H.; Sasaki, T.; Shimizu, Y.; Koshizaki, N.; Kanesato, M. Adv. Mater. 2005, 17, 606.

(103) Lavastre, O.; Illitchev, I.; Jegou, G.; Dixneuf, P. H. J. Am. Chem. Soc. 2002, 124, 5278.

(104) (a) Leung, A. C. W.; Chong, J. H.; Patrick, B. O.; MacLachlan, M. J. Macromolecules 2003, 36, 5051. (b) Leung, A. C. W.; MacLachlan, M. J. J. Mater. Chem. 2007, 17, 1923.

(105) Sun, S.; Tong, W-L.; Chan, M. C. W. Macromol. Rapid Commun. 2010, 31, 1965.

(106) Zhao, C.; Sun, S.; Tong, W-L.; Chan, M. C. W. Macromolecules 2017.

(107) Wang, J.; Huang, W.; Pan, L.; Wang, H.; Zhang, C.; Liu, X. Macromol. Res. 2015, 23, 309.

(108) Chantarasiri, N.; Tuntulani, T.; Tongraung, P.; SeangprasertkitMagee, R.; Wannarong, W. Eur. Polym. J. 2000, 36, 695.

(109) Jiang, J.; Leung, A. C. W.; MacLachlan, M. J. Dalton Trans. 2010, $39,6503$.

(110) (a) Luo, R.; Zhou, X.; Chen, S.; Li, Y.; Zhou, L.; Ji, H. Green Chem. 2014, 16, 1496. (b) Leng, Y.; Lu, D.; Zhang, C.; Jiang, P.; Zhang, W.; Wang, J. Chem. Eur. J. 2016, 22, 8368. (c) Luo, R.; Chen, Y.; He, Q.; Lin, X.; Xu, Q.; He, X.; Zhang, W.; Zhou, X.; Ji, H. ChemSusChem 2017, 10, 1526.

(111) Nielsen, M.; Thomsen, A. H.; Jensen, T. R.; Jakobsen, H. J.; Skibsted, J.; Gothelf, K. V. Eur. J. Org. Chem. 2005, 2005, 342.

(112) Li, L-H.; Feng, X-L.; Cui, X-H.; Ma, Y-X.; Ding, S-Y.; Wang, W. J. Am. Chem. Soc. 2017, 139, 6042.

(113) (a) Han, X.; Xia, Q.; Huang, J.; Liu, Y.; Tan, C.; Cui, Y. J. Am. Chem. Soc. 2017, 139, 8693. (b) Li, H.; Feng, X.; Shao, P. P.; Chen, J.; Li, C. Z.; Jayakumar, S.; Yang, Q. H. J. Mater. Chem. A 2019, 7, 5482.

(114) (a) Haak, R. M.; Castilla, A. M.; Belmonte, M. M.; EscuderoAdán, E. C.; Benet-Buchholz, J.; Kleij, A. W. Dalton Trans. 2011, 40, 3352. (b) Escudero-Adán, E. C.; Benet-Buchholz, J.; Kleij, A. W. Inorg. Chem. 2007, 46, 7265.

(115) Elbert, S. M.; Zhang, W-S.; Vaynzof, Y.; Oberhof, N.; Bernhardt, M.; Pernpointner, M.; Rominger, F.; Schröder, R. R.; Mastalerz, M. Chem. Mater. 2019, 31, 6210.

(116) Elbert, S. M.; Rominger, F.; Mastalerz, M. Chem. Eur. J. 2014, 20 , 16707.

(117) Johnson, J. A.; Chen, S.; Reeson, T. C.; Chen, Y-S.; Zeng, X. C.; Zhang, J. Chem. Eur. J. 2014, 20, 7632.

(118) (a) Li, H.; Xu, B.; Liu, X., A S, He, C.; Xia, H.; Mu, Y. J. Mater. Chem. A 2013, 1, 14108. (b) Xie, Y.; Wang, T-T.; Liu, X-H.; Zou, K.; Deng, W-Q. Nat. Commun. 2013, 4, 1960. (c) Li, H.; Li, Z.;
Zhang, Y.; Luo, X.; Xia, H.; Liu, X.; Mu, Y. RSC Adv. 2014, 4, 37767. (d) Liu, T. T.; Lin, Z. J.; Shi, P. C.; Ma, T.; Huang, Y. B.; Cao, R. ChemCatChem 2015, 7, 2340. (e) Alkordi, M. H.; Weseliński, ŁJ.; D’Elia, V.; Barman, S.; Cadiau, A.; Hedhili, M. N.; Cairns, A. J.; AbdulHalim, R. G.; Basset, J-M.; Eddaoudi, M. J. Mater. Chem. A 2016, 4, 7453.

(119) (a) Gupta, K. C.; Abdulkadir, H. K.; Chand, S. J. Mol. Catal. A: Chem. 2003, 202, 253. (b) Alvaro, M.; Baleizao, C.; Carbonell, E.; El Ghoul, M.; García, H.; Gigante, B. Tetrahedron 2005, 61, 12131.

(120) Wang, R-M.; Hao, E-X.; Shen, G-R.; He, Y-F.; Lei, Z-Q. J. Appl. Polym. Sci. 2009, 111, 1999.

(121) (a) Côté, A. P.; Benin, A. I.; Ockwig, N. W.; O’Keeffe, M.; Matzger, A. J.; Yaghi, O. M. Science 2005, 310, 1166. (b) Ding, S-Y.; Wang, W. Chem. Soc. Rev. 2013, 42, 548. (c) Diercks, C. S.; Yaghi, O. M. Science 2017, 355.

(122) Mastalerz, M.; Oppel, I. M. Eur. J. Org. Chem. 2011, 5971.

(123) Mastalerz, M.; Hauswald, H-JS.; Stoll, R. Chem. Commun. 2012, $48,130$.

(124) Yan, S.; Guan, X.; Li, H.; Li, D.; Xue, M.; Yan, Y.; Valtchev, V.; Qiu, S.; Fang, Q. J. Am. Chem. Soc. 2019, 141, 2920.

(125) Huang, J.; Han, X.; Yang, S.; Cao, Y.; Yuan, C.; Liu, Y.; Wang, J.; Cui, Y. J. Am. Chem. Soc. 2019, 141, 8996.

(126) Liu, H.; Feng, J.; Zhang, J.; Miller, P. W.; Chen, L.; Su, C-Y. Chem. Sci. 2015, 6, 2292.

(127) Reinhard, D.; Zhang, W-S.; Vaynzof, Y.; Rominger, F.; Schröder, R. R.; Mastalerz, M. Chem. Mater. 2018, 30, 2781.

(128) Chun, J.; Kang, S.; Kang, N.; Lee, S. M.; Kim, H. J.; Son, S. U. J. Mater. Chem. A 2013, 1, 5517.

(129) Wöhrle, D.; Bohlen, H.; Rothkopf, H. W. Makromol. Chem. 1983, 184, 763.

(130) Krishnan, R.; Vancheesan, S. J. Mol. Catal. A: Chem. 2000, 157, 15.

(131) (a) Martín, C.; Fiorani, G.; Kleij, A. W. ACS Catal. 2015, 5, 1353. (b) Decortes, A.; Castilla, A. M.; Kleij, A. W. Angew. Chem. Int. Ed. 2010, 49, 9822.

(132) Liu, T-T.; Liang, J.; Huang, Y-B.; Cao, R. Chem. Commun. 2016, 52, 13288.

(133) Bhunia, S.; Molla, R. A.; Kumari,V.; Islam, S. M.; Bhaumik, A.Chem. Commun. 2015, 51, 15732. It is worth mentioning that for similar transformations much higher TONs of up to 2000 and TOFs of $1000 \mathrm{~h}^{-1}$ were found for MOF-based heterogenous catalysts, as seen in: Zhou, Z.; He, C; Xia, J; Yang, L; Duan, C. J. Am. Chem. Soc. $2015,137,15066$. For comparable homogenous catalysts, TONs as high as 112000 and TOFs up to $36000 \mathrm{~h}^{-1}$ are reported as seen in: Whiteoak, C.J.; Kleij, A.W. Synlett. 2013, 24, 1748.

(134) Kleij, A. W. Dalton Trans. 2009, 4635.

(135) Katsuki, T. J. Synth. Org. Chem. Jpn. 1995, 53, 940.

(136) (a) Liu, P.; Feng, X-J.; He, R. Tetrahedron 2010, 66, 631. (b) Gogoi, A.; Dewan, A.; Borah, G.; Bora, U. New J. Chem. 2015, 39, 3341. (c) Borhade, S. R.; Waghmode, S. B. Tetrahedron Lett. 2008, 49, 3423.

(137) Li, J. R.; Yu, J. M.; Lu, W. G.; Sun, L. B.; Sculley, J.; Balbuena, P. B.; Zhou, H. C. Nat. Commun. 2013, 4, 1538.

(138) (a) Vaidhyanathan, R.; Iremonger, S. S.; Dawson, K. W.; Shimizu, G. K. H. Chem. Commun. 2009, 5230. (b) Dietzel, P. D. C.; Besikiotis, V.; Blom, R. J. Mater. Chem. 2009, 19, 7362. (c) Dietzel, P. D. C.; Johnsen, R. E.; Fjellvåg, H.; Bordiga, S.; Groppo, E.; Chavan, S.; Blom, R. Chem. Commun. 2008, 5125.

(139) (a) Min Wang, Q.; Shen, D.; Bülow, M.; Ling Lau, M.; Deng, S.; Fitch, F. R.; Lemcoff, N. O.; Semanscin, J. Microporous Mesoporous Mater. 2002, 55, 217. (b) Farrusseng, D.; Daniel, 
C.; Gaudillère, C.; Ravon, U.; Schuurman, Y.; Mirodatos, C.; Dubbeldam, D.; Frost, H.; Snurr, R. Q. Langmuir 2009, 25, 7383.

(140) Volkringer, C.; Loiseau, T.; Haouas, M.; Taulelle, F.; Popov, D.; Burghammer, M.; Riekel, C.; Zlotea, C.; Cuevas, F.; Latroche, M.; Phanon, D.; Knöfelv, C.; Llewellyn, P. L.; Férey, G. Chem. Mater. 2009, 21, 5783.

(141) Tong, W-L.; Lai, L-M.; Chan, M. C. W. Dalton Trans. 2008, (11): 1412.

(142) The enantiomeric fluorescence difference ratio (ef) is defined as the ratio in fluorescence intensity of the sensoric polymer at similar concentration of each enantiomer..

(143) Song, F.; Wei, G.; Wang, L.; Jiao, J.; Cheng, Y.; Zhu, C.J. Org. Chem. 2012, 77, 4759.

(144) (a) Alaerts, L.; Maes, M.; Giebeler, L.; Jacobs, P. A.; Martens, J. A.; Denayer, J. F. M.; Kirschhock, C. E. A.; De Vos, D. E. J. Am. Chem. Soc. 2008, 130, 14170. (b) Finsy, V.; Verelst, H.; Alaerts, L.; De Vos, D.; Jacobs, P. A.; Baron, G. V.; Denayer, J. F. M. J. Am. Chem. Soc. 2008, 130, 7110. (c) Holcroft, J. M.; Hartlieb, K. J.; Moghadam, P. Z.; Bell, J. G.; Barin, G.; Ferris, D. P.; Bloch, E.
D.; Algaradah, M. M.; Nassar, M. S.; Botros, Y. Y.; Thomas, K. M.; Long, J. R.; Snurr, R. Q.; Stoddart, J. F. J. Am. Chem. Soc. 2015, 137, 5706. (d) Moreira, M. A.; Santos, J. C.; Ferreira, A. F. P.; Loureiro, J. M.; Ragon, F.; Horcajada, P.; Shim, K-E.; Hwang, Y-K.; Lee, U. H.; Chang, J-S.; Serre, C.; Rodrigues, A. E. Langmuir 2012, 28, 5715. (e) Moreira, M. A.; Santos, J. C.; Ferreira, A. F. P.; Loureiro, J. M.; Ragon, F.; Horcajada, P.; Yot, P. G.; Serre, C.; Rodrigues, A. E. Microporous Mesoporous Mater. 2012, 158, 229. (f) Moreira, M. A.; Santos, J. C.; Ferreira, A. F. P.; Loureiro, J. M.; Ragon, F.; Horcajada, P.; Yot, P. G.; Serre, C.; Rodrigues, A. E. Langmuir 2012, 28, 3494. (g) Moreira, M. A.; Santos, J. C.; Ferreira, A. F. P.; Loureiro, J. M.; Rodrigues, A. E.Ind. Eng. Chem. Res. 2011, 50, 7688. (h) Moreira, M. A.; Santos, J. C.; Ferreira, A. F. P.; Müller, U.; Trukhan, N.; Loureiro,J. M.; Rodrigues, A. E.Sep. Sci. Technol. 2011, 46, 1995. (i) Moreira, M. A.; Santos, M. P. S.; Silva, C. G.; Loureiro, J. M.; Chang, J-S.; Serre, C.; Ferreira, A. F. P.; Rodrigues, A. E. Adsorption 2018, 24, 715. (j) Nicolau, M. P. M.; Bárcia, P. S.; Gallegos, J. M.; Silva, J. A. C.; Rodrigues, A. E.; Chen, B.J.Phys. Chem. C 2009, 113, 13173. (k) Yang, C-X.; Yan, X-P. Anal. Chem. 2011, 83,7144 . 